\title{
CRENAS
}

CENTRO RICERCHE

ECONOMICHE NORD SUD

Università di Cagliari

Università di Sassari

\section{BANKS, FINANCIAL MARKETS AND GROWTH}

$$
\text { Luca Deidda }
$$

Bassam Fattouh 


\title{
Banks, Financial Markets and Growth*
}

\author{
Luca Deidda \\ Centre for Financial and Management Studies, SOAS, and CRENoS \\ Bassam Fattouh \\ Centre for Financial and Management Studies, SOAS \\ This version: October 2005
}

\begin{abstract}
We analyze the interaction between bank and market finance in a model where bankers gather information through monitoring and screening. We show that, if a market is established characterized by a disclosure law such that entrepreneurs wishing to raise market finance can credibly disclose their sources of financing, this might undermine bankers' incentive to screen, even when screening is efficient. Correspondingly, other things being equal, the change from a bank-based system to one in which market-finance and bank-finance coexist might have an adverse affect on economic growth. Consistent with this result, our empirical findings suggest that, although both bank and stock market development have a positive effect on growth, the growth impact of bank development is reduced by the development of the stock market.
\end{abstract}

Keywords: Bank-finance, Market-finance, Economic Growth, Monitoring, Screening

JEL classification: G10, G20, E44, O40

${ }^{*}$ We would like to thank an anonymous referee, Hong Bo, Sonja Ruhel, Pasquale Scaramozzino and Laixiang Sun for their useful comments. Corresponding author: Luca Deidda, SOAS, University of London, Thornhaugh Street, London, WC1H 0XG, United Kingdom. E-Mail: LD1@SOAS.AC.UK 


\section{Introduction}

The large body of literature on finance and growth offers several explanations as to why financial institutions facilitate economic growth. ${ }^{1}$ Financial institutions mobilize savings, diversify risk and produce information about investment opportunities. These functions help to improve the productivity of financed investments, which should result in higher growth rates provided that the returns to accumulable inputs are non-diminishing at an aggregate level. Consistent with this theoretical proposition, several empirical studies find that financial development can be strongly related to the process of economic growth, although the strength and the sign of such a relationship might vary with the level of economic development and other country-specific factors. ${ }^{2}$

An important aspect of the relationship between finance and growth is the way in which the financial structure, proxied by the importance of financial institutions such as banks relative to financial markets, affects the allocation of financial resources. Crucially relevant to this issue is the observation that when markets are incomplete, financial institutions and capital markets might affect each other in a non trivial way. For instance, Allen and Gale (1997) demonstrate that while banks can provide more effective intertemporal risk smoothing than financial markets, their effectiveness in performing this role crucially depends on the degree of competition from the markets. Strong competition might result in disintermediation, undermining banks' ability to provide intertemporal risk smoothing.

In this paper, we study the interaction between financial investors that gather information about investment opportunities and a financial market where information is disclosed, and derive the consequences for the allocation of financial resources. We find that the establishment of a financial market characterized by a disclosure law such that entrepreneurs wishing to raise finance can credibly disclose their sources of financing, may undermine institutions' incentives to screen the quality of the investments they finance. This might occur even if screening would have been efficient. Applying this result in the context of a growth model, we show that, other things being equal, the change in the financial structure resulting from the introduction of such disclosure law could affect the equilibrium growth rate of the economy in an adverse way.

We construct a simple model of a competitive financial system in which financial investors provide funds to entrepreneurs. Financial investors can monitor (and screen) the entrepreneurs they fund, in which case we call them bankers. Alternatively, they can purchase financial securities, in which case we call them market investors. Entrepreneurs can either rely on bankers to finance their investments (bank-finance) or issue financial securities in the market (market-finance), or both.

\footnotetext{
${ }^{1}$ Seminal contributions include Greenwood and Jovanovic (1990), Saint-Paul (1992), Bencivenga and Smith (1991). Pagano (1993) and Levine (1997) survey this literature.

${ }^{2}$ See King and Levine (1993) for an early contribution. Non linear studies include Christopoulos and Tsionas (2004), Deidda and Fattouh (2002) and Harris (1997).
} 
We first present a set up in which the main source of imperfect information is that entrepreneurs' investment decisions are private, i.e. non observable by third parties. This gives rise to a moral hazard problem since by assumption entrepreneurs have the incentive to choose negative net present value (NPV) investments. Accordingly, there is scope for bankers to monitor, which would eliminate the moral hazard issue. Monitoring is costly, nonverifiable and nonobservable. Thus, similar to the model by Holmstrom and Tirole (1997), bankers need to be given the incentive to monitor. Because of monitoring costs, bank-finance is always more expensive than market-finance, and thus entrepreneurs aim at minimizing its use. On the other hand, financial investors are willing to supply marketfinance only if they know that the entrepreneurs are being monitored. Since monitoring costs are fixed, a banker has the incentive to monitor an entrepreneur if and only if the amount of finance supplied by the banker to that entrepreneur does not fall below a certain minimum. Therefore, the amount of bank-finance raised by an entrepreneur is informative of whether that entrepreneur will be monitored. If the financial market enforces a disclosure law, entrepreneurs can credibly disclose their sources of financing, so that they have access to market-finance. In this case, entrepreneurs' equilibrium capital structure is a mixture of market-finance and bank-finance, where the latter is kept at a minimum. Otherwise, without disclosure law, entrepreneurs cannot credibly disclose their sources of financing and market-investors are not informed on whether entrepreneurs are monitored or not, so that bank finance is the only source of finance.

In this simple model, the interaction between bank-finance and market-finance is irrelevant: the NPV of financed investment does not depend on whether the financial system comprises both market and bank finance or only the latter.

A different conclusion is reached when the following additional assumptions are introduced: a. There exist two qualities of investment yielding a positive NPV, with the better quality being associated with higher expected NPV; b. The quality of investments is observable only by incurring a fixed screening cost. ${ }^{3}$ Similarly to monitoring, a banker has the incentive to screen the quality of an entrepreneur's projects if and only if the finance supplied by the banker to that entrepreneur is enough to recover the fixed screening costs, given the expected gain due to the selection of high quality investments through the screening. Therefore, the amount of bank-finance raised by an entrepreneur is not just informative of whether that entrepreneur will be monitored or not, but also of whether her investments have been subject to screening or not. Still, if there is no disclosure law, entrepreneurs cannot credibly disclose their sources of financing to market investors. Therefore, bank-finance will be the only source of financing. Under these circumstances, bankers internalize all the benefits from screening and therefore provide the efficient level of screening. Differently, when the disclosure law is in place, market investors become informed and the entrepreneurs can minimize the use of bank-finance by gaining access to

\footnotetext{
${ }^{3}$ Manove, Padilla and Pagano (2001) consider a model in which banks either just monitor borrowers or also screen applicants.
} 
market-finance. This might lead to an equilibrium in which the demand for bank-finance is so low that no screening takes place, even when screening would be efficient. Not all benefits from the screening process are internalized by bankers who incur the cost. By disclosing their sources of financing, entrepreneurs indirectly reveal the quality of their investment and as a result, market investors capture part of the benefits from screening without incurring any cost. This explains why an inefficient level of screening can occur.

We find that, given the screening cost, for intermediate levels of the return to investment, either only a pooling equilibrium exists with no screening, irrespective of whether screening would have been efficient or not, or the pooling equilibrium coexists with the screening equilibrium. Only if the return on the best quality projects is sufficiently high, the equilibrium is always characterized by the efficient level of screening.

These conclusions are incorporated in a simple overlapping generation model to show that, other things equal, the change from a system in which bank-finance is the only source of financing to a system characterized by the interaction between bank and market finance could have a negative effect on economic growth. This theoretical result has important implications for the 'financial structure and growth' debate (see Dolar and Meh (2002) for a recent review). A common view in this debate, is that while "[...] Better-developed financial systems positively influence growth. It is relatively unimportant for economic growth [..] whether overall financial development stems from bank or market development [...]", (Levine, 2002, p.400). This conclusion, which is referred to as the 'financial service view' has received empirical support from cross-section econometric studies such as Beck and Levine (2002) and Demirguc-Kunt and Levine (2001). ${ }^{4}$

Contrary to this view, our model predicts that as long as banks and market have distinct roles in the provision of information then the interaction between them may have an impact on growth. We analyze the growth impact of the interaction between stock market and banks using the same data set as Demirguc-Kunt and Levine (2001). Our empirical findings confirm the established result that both banking and stock market development are positively associated with higher real per capita growth. This positive relationship, however, hides some interesting interaction effects between these two components of the financial system, which have not been fully explored in the empirical literature. In particular, by modifying the standard cross-country growth regression model to include an interaction term between banking and stock market development we find that the growth impact of banking development is affected by the development of the stock market. Specifically, our results show a significant negative interaction effect implying that the impact of banking development on growth becomes less positive the higher is the level of stock market development. This is highly robust to alternative specifications and instrumen-

\footnotetext{
${ }^{4}$ Empirical analyzes based on panel data at industry-level challenge this empirical result. For instance, Tadesse (2002) finds that in countries with relatively underdeveloped financial systems, bank based systems seem to outperform market based systems. The opposite is also true, for countries with relatively highly developed financial systems.
} 
tal variables estimation. This finding is consistent with the model's conclusion that the interaction between bank and market-finance matters for growth.

The paper is organized as follows. Section 2 presents a model where bankers perform only monitoring, while Section 3 introduces screening. Section 4 analyzes the implications for long run economic growth. Section 5 presents the empirical evidence. A final section concludes the paper.

\section{Market and bank-finance with monitoring}

The economy is populated by a continuum of size $N$ of identical entrepreneurs and by a continuum of size $S$ of identical financial investors, with $N>S$. Both entrepreneurs and financial investors are risk-neutral. Financial investors are endowed with one unit of financial wealth each and can either finance entrepreneurs' investment activity or invest themselves in a safe asset that yields a return $\gamma$. Entrepreneurs, who have no financial wealth, can operate at most one investment project each. Two types of investment projects are available, $G$ and $B$, satisfying the following properties:

$i$. A type $G$ project yields a rate of return $r$ with probability $g$, and zero otherwise, while bringing no private benefits to the entrepreneur;

ii. A type $B$ project yields a rate of return $r$ with probability $b$ and zero otherwise, and bring $B>0$ as private benefits to the entrepreneur;

iii. Independently of its type, each project needs one unit of financial resources (financial capital). Having assumed that entrepreneurs have no financial resources, that is also the amount of external financial resources needed by each entrepreneur;

iv. $b<g$ and $r b+B<\gamma<r g$ : only type- $G$ projects have a positive Net Present Value $(\mathrm{NPV})$.

Entrepreneurs' individual choice of project's type is private information. In other words, financial investors cannot directly observe whether an individual entrepreneur has chosen a project of type $B$ or $G$. However, they can observe such a choice by incurring a monitoring cost $c$ per project.

Financial investors have three alternative means of investing their financial resources: a. Become market investors who purchase financial securities issued by entrepreneurs; b. Become bankers who can acquire private information about the type of the financed investments through monitoring; $c$. Invest in the safe asset that yields $\gamma$. We define bankfinance the finance provided by bankers, and market-finance that provided by market investors. Accordingly, entrepreneurs' capital structure is defined in terms of the composition of bank-finance, $l$, and market-finance, $e$, where for each unit of financial capital, $e+l=1$ holds. 
While we assume that ex-post returns are perfectly observable, monitoring is nonverifiable and nonobservable. Since monitoring costs per unit of capital are fixed, for each banker, the incentive to monitor an entrepreneur will depend upon the contribution made by the banker to the financing needs of that entrepreneur. ${ }^{5}$ Accordingly, whether an entrepreneur will be monitored or not can be perfectly inferred by observing the capital structure of the entrepreneur and, in particular, the amount of bank-finance provided by individual bankers.

Entrepreneurs' information on sources of financing constitutes private information. However, entrepreneurs can credibly disclose such information if the financial market is characterized by a disclosure law. The idea is that the disclosure law ensures that: a. The information about the sources of financing reported by the entrepreneurs wishing to raise market-finance is truthful; b. Entrepreneurs have to report all the relevant information.

Financial markets where market and bank finance are exchanged are competitive. Agents are price-takers, so that they take the returns per unit of bank and market finance as given.

\subsection{Moral hazard and monitoring}

Since entrepreneurs have no internal sources of finance and no collateral to back up external financing, financial investors strongly dislike financing projects of type $B$, which yield a negative NPV. ${ }^{6}$ Nevertheless, entrepreneurs might have the incentive to choose this type of projects because of the associated private benefits. Accordingly, there is a potential moral hazard problem. If choosing a type-B project, the expected profits of the entrepreneur are $\left(r-r_{\text {wacc }}\right) b+B$, while the expected profits associated with a type-G project are $\left(r-r_{\text {wacc }}\right) g$, where

$$
r_{\text {wacc }}=r_{l} l+r_{e} e
$$

is the weighted average cost of a unit of financial capital (wacc) faced by the entrepreneur, and $r_{l}$ and $r_{e}$ are the returns promised to bankers and market investors, respectively.

Given the expected profits associated with the alternative types of investment, an entrepreneur has a strong incentive to choose type $B$ projects whenever

$$
\left(r-r_{w a c c}\right) b+B>\left(r-r_{w a c c}\right) g \Leftrightarrow r_{w a c c}>r-\frac{B}{\Delta} .
$$

Entrepreneurs prefer type- $G$ projects if the reverse inequality holds. We want moral hazard to be pervasive meaning that in any equilibrium, $r_{w a c c}>r-B / \Delta$ holds. Accordingly, we impose $\gamma / g>r-B / \Delta$ which, as shown later, is a sufficient condition for that to happen.

By incurring a monitoring cost $c$ per project, bankers observe the type of project chosen by entrepreneurs, in which case they can enforce the choice of projects of type

\footnotetext{
${ }^{5}$ This feature of the model is equivalent to that put forward by Holmstrom and Tirole (1997).

${ }^{6}$ Since $r b+B<\gamma$, of a pool of financial investors financing a type $B$ project, at least one of them must be receiving an expected return lower than the opportunity cost of capital, $\gamma$, in expected terms.
} 
$G$ as a condition for supplying finance. We assume that returns are perfectly correlated across projects. ${ }^{7}$ Accordingly, given that monitoring activity is nonverifiable, bankers are themselves subject to a potential moral hazard problem. This becomes specially relevant when an entrepreneur is financed both by bankers and market investors.

Given the amount of bank-finance demanded by an entrepreneur, $l^{d}$, and the promised return per unit of bank-finance, $r_{l}$, the incentive compatibility condition for a banker to monitor is

$$
g r_{l} l^{d}-c \geq b r_{l} l^{d}
$$

where the LHS and the RHS denote the expected profits of the banker in the presence and absence of monitoring, respectively. Solving for $r_{l} l^{d}$ yields

$$
r_{l} l^{d} \geq \frac{c}{\Delta}
$$

That is, in equilibrium, the overall payment promised to a banker, $r_{l} l^{d}$, must not be lower than some critical amount if the banker is to monitor.

\subsection{Equilibrium analysis}

Definition 1 An equilibrium with financial exchange is a pair of returns $\left(r_{l}^{*}, r_{e}^{*}\right)$ to be paid to bank and market finance respectively, such that:

i. Given returns, individual financial investors and entrepreneurs take their financial/investment decisions so as to maximize their expected payoff;

ii. The aggregate demand and supply of market and bank finance are such that the markets for bank and market finance both clear.

In order to characterize the equilibrium, we analyze the individual behavior of financial investors and entrepreneurs and derive the related supply and demand schedules for market and bank finance. We first focus on financial investors.

When operating as bankers, financial investors choose whether to monitor financed investment or not so to maximize the net return. Correspondingly, given the bank-finance demanded by each entrepreneur, $l^{d}$, bankers' expected return per unit of bank-finance net of costs is

$$
\pi_{b}=\max \left(g r_{l}-\frac{c}{l^{d}}, b r_{l}\right) .
$$

When operating as market investors, given the promised return per unit of marketfinance, $r_{e}$, their expected return is $E\left(r_{e}\right)$, where $E\left(r_{e}\right)$ equals $g r_{e}$ or $b r_{e}$ depending on

\footnotetext{
${ }^{7}$ Some degree of correlation greater than zero is needed to justify why bankers cannot credibly commit to monitor unless they are supplying enough funds to the entrepreneur as, with no correlation, each banker could achieve full risk diversification by financing a continuum of projects (see also Holmstrom and Tirole, 1997). Assuming perfect correlation simplifies the analysis. An alternative approach could be to assume that each banker can monitor at most one project.
} 
whether the entrepreneurs issuing the related financial securities are investing in projects of type $G$ or $B$.

Define $l^{s}$ and $e^{s}$ as the amounts of bank and market finance respectively, supplied by a financial investor. Then, since each financial investor allocates her unitary endowment of financial resources in order to maximize the expected return, and given the return on the safe asset, $\gamma$,

$$
\begin{gathered}
l^{s}= \begin{cases}1 & \text { if } \pi_{b}>\max \left(E\left(r_{e}\right), \gamma\right) \\
{[0,1]} & \text { if } \pi_{b}=\max \left(E\left(r_{e}\right), \gamma\right) \\
0 & \text { if } \pi_{b}<\max \left(E\left(r_{e}\right), \gamma\right)\end{cases} \\
e^{s}= \begin{cases}1 & \text { if } E\left(r_{e}\right)>\max \left(\pi_{b}, \gamma\right) \\
{[0,1]} & \text { if } E\left(r_{e}\right)=\max \left(\pi_{b}, \gamma\right) \\
0 & \text { if } E\left(r_{e}\right)<\max \left(\pi_{b}, \gamma\right)\end{cases}
\end{gathered}
$$

where $l^{s}+e^{s}=1$ must hold. According to the above notation, when $l^{s}=e^{s}=0$, financial investors are investing in the safe asset only. Note that given the amount of bank-finance demanded by each entrepreneur, $l^{d}$, a financial investor supplying $l^{s}$ units of bank-finance is financing a measure $l^{s} / l^{d} \geq 0$ of entrepreneurs. Aggregate supply of bank finance is found by integrating (6) over the interval $[0, S]$, which yields $S l^{s}$. Correspondingly, aggregate supply of market finance is $S\left(1-l^{s}\right)$.

Entrepreneurs choose whether to demand finance and which type of finance, i.e. marketfinance or bank-finance or both. Clearly, they only demand finance if the expected return from investment, net of the cost of capital, is positive. For instance, if investing in a project of type $G$, her expected profits are $g\left(r-r_{\text {wacc }}\right)$. Therefore, conditional on the choice of a type $G$ project, the total demand for finance by each entrepreneur is

$$
l^{d}+e^{d}=\left\{\begin{array}{ll}
1 & \text { if } r_{w a c c}<r \\
0 \text { or } 1 & \text { if } r_{w a c c}=r \\
0 & \text { if } r_{w a c c}>r
\end{array} .\right.
$$

On the other hand, if the entrepreneur were choosing a type $B$ project, demand for finance will be positive if $r_{\text {wacc }} \leq r+B / b$ and zero otherwise.

Important to the analysis of the entrepreneurial choice of bank-finance versus marketfinance is the following

Lemma 1 Moral hazard is pervasive: In any equilibrium with financial exchange, entrepreneurs have a strong incentive to choose type $B$ projects.

Proof. See appendix.

The fact that moral hazard is pervasive means that, in the absence of the disclosure law, in equilibrium, entrepreneurs cannot credibly commit to choose type $G$ projects, even if they wanted to. So long as the choice of project's type is private information, entrepreneurs have always the incentive to choose type $B$ projects even if they announce otherwise. The 
only way investors can make sure that entrepreneurs choose type $G$ projects is to monitor them, in which case the choice of projects $G$ can be enforced as a condition for obtaining finance.

It follows from equation (4) that entrepreneurs will be subject to monitoring if $l^{d} \geq$ $c / \Delta r_{l}$. Hence, in the presence of the disclosure law entrepreneurs can signal to market investor their choice of type $G$ projects by demanding (and disclosing) an amount of bank finance $l^{d} \geq c / \Delta r_{l}$. Since the disclosure law ensures the truthfulness of the disclosed information, the disclosed level of bank-finance, $l^{d}$, is informative of whether the entrepreneur is monitored or not. ${ }^{8}$

A reason why an entrepreneur might have an incentive to demand $l^{d} \geq c / \Delta r_{l}$ is to gain access to cheaper market finance. Let $r_{e}$ be the rate of return that an entrepreneur disclosing an amount of market finance $l^{d} \geq c / \Delta r_{l}$ has to guarantee to market investors. Then, entrepreneurs who demand an amount of market finance lower than $c / \Delta r_{l}$ would have to guarantee a return $r_{e} g / b$, which is strictly greater than $r_{e}$, since $g>b$. This is case because market investors, on the basis of lemma 1, correctly anticipate that such entrepreneurs are not subject to monitoring and therefore will choose type $B$ projects, which have a probability of success equal to $b$.

Correspondingly, in the presence of the disclosure law, given $r_{l}$ and $r_{e}$,

$$
r_{w a c c}=\left\{\begin{array}{ll}
r_{l} l^{d}+\left(1-l^{d}\right) r_{e} & \text { if } l^{d} \geq \frac{c}{\Delta r_{l}} \\
r_{l} l^{d}+\left(1-l^{d}\right) \frac{r_{e} g}{b} & \text { if } l^{d}<\frac{c}{\Delta r_{l}}
\end{array} .\right.
$$

Accordingly, since entrepreneurs aim at minimizing the cost of capital, demand of bank and market finance by individual entrepreneurs are as follows:

$$
l^{d}=\left\{\begin{array}{ll}
1 & \text { if } r_{e}>r_{l} \\
{\left[\min \left(\frac{c}{\Delta r_{l}}, 1\right), 1\right]} & \text { if } r_{e}=r_{l} \\
\min \left(\frac{c}{\Delta r_{l}}, 1\right) & \text { if } r_{l}>r_{e} \text { and }\left.r_{w a c c}\right|_{l^{d}=\min \left(\frac{c}{\Delta r_{l}}, 1\right)}<\left.r_{w a c c}\right|_{l^{d}=0} \\
0 & \text { if } r_{l}>r_{e} \text { and }\left.r_{\text {wacc }}\right|_{l^{d}=\min \left(\frac{c}{\Delta r_{l}}, 1\right)}>\left.r_{w a c c}\right|_{l^{d}=0}
\end{array} .\right.
$$

Note that a necessary condition for entrepreneurs to demand an amount of bankfinance lower than $c / \Delta r_{l}$ is $r_{l}>r_{e} g / b$. In this case, if choosing $l^{d}<c / \Delta r_{l}$, the optimal strategy would be to set $l^{d}=0$ and use only market-finance. Given (10), the demand for market-finance, $e^{d}=1-l^{d}$, directly follows. Finally, aggregate demand of bank-finance is found by integrating $l^{d}$ over the interval $[0, N]$, which yields $N l^{d}$. Correspondingly, the aggregate demand of market-finance is $N\left(1-l^{d}\right)$.

The above signaling mechanism does not work in the absence of the disclosure law. Entrepreneurs who announce $l^{d} \geq c / \Delta r_{l}$ to get access to cheaper market finance would always then have the incentive to cheat by financing themselves just with market-finance

\footnotetext{
${ }^{8}$ In other words, the disclosure law prevents entrepreneurs from misreporting information (cheating) on their sources of financing. Hence, the information disclosed is credible, and the level of financing becomes a meaningful commitment device.
} 
(if any market-finance is available), which would also enable them to choose projects of type $B$, which according to Lemma 1 , they strictly prefer. In other words, the disclosure of $l^{d} \geq c / \Delta r_{l}$ would not be credible, since there is no law to ensure the truthfulness of the disclosed information and entrepreneurs have the incentive to cheat. It then follows that, without the disclosure law, the return (which will be determined in equilibrium) that an entrepreneur should guarantee to market investors, $r_{e}$, is independent of the amount of bank-finance demanded by that entrepreneur. Under these circumstances, entrepreneurs choose to use just bank-finance (market-finance) so long as $r_{l}>(<) r_{e}$ and will be indifferent between the two sources of finance if $r_{l}=r_{e}$.

Given the schedules of demand and supply of finance,

Proposition 1 No financial exchange is the unique equilibrium outcome if $r<(\gamma+c) / g$. Viceversa, if $r>(\gamma+c) / g$ the unique equilibrium outcome is financial exchange. Given $r>(\gamma+c) / g$, in any equilibrium, $S$ is aggregate amount of financial exchange and $r_{\text {wacc }}=r$ holds. Moreover,

i. Without the disclosure law: $l^{d *}=1$ and $r_{l}^{*}=r$;

ii. With the disclosure law: $l^{d *}=\frac{c}{\Delta r_{l}^{*}}<1, r_{e}^{*}=r-\frac{c}{g} ; r_{l}^{*}=\left(r-\frac{c}{g}\right) \frac{g}{b}$.

Proof. See appendix.

Both in the presence and in the absence of the disclosure law, the NPV generated through the investment activity made possible by financial exchange would be $g r-c$ per unit of finance. Whether financial exchange takes the form of both bank and market finance or bank-finance alone does not have any real effect. Financial structure is just a veil: what matters is the presence of a financial system that guarantees financial exchange; whether bank-finance dominates or bank and market finance coexist does not make any difference. Notably, there is a complementarity relationship running from bank-finance to market-finance: a necessary condition for the exchange of market-finance is that entrepreneurs are monitored by bankers, which in turn implies that bankers are providing enough finance to have the incentive to monitor. Yet, this complementarity relationship has no consequences on the NPV of financed investments.

\section{Market and bank-finance with monitoring and screen- ing}

We now enrich our model by introducing a new source of informational imperfection. We assume that projects of type $G$ come in two different qualities: $\bar{G}$ and $\underline{G}$. Quality $\bar{G}$ projects have a probability of success $\bar{g}$ while quality $\underline{G}$ have a probability of success $\underline{g}$, with $\bar{g}>\underline{g} .{ }^{9}$ The quality of type $G$ projects cannot be observed directly. Hence, when

\footnotetext{
${ }^{9}$ Whether we assume that projects of quality $\underline{G}$ have positive NPV or not is irrelevant.
} 
operating projects of type $G$, entrepreneurs are not able to select quality $\bar{G}$. However, by incurring a fixed cost screening cost $s$, bankers can observe such quality.

We assume that, conditional on choosing a project of type $G$, the probability to select a quality $\bar{G}$ is $\lambda$; with probability $1-\lambda$ a quality $\underline{G}$ is selected. Accordingly, $g \equiv \lambda \bar{g}+(1-\lambda) \underline{g}$ is the ex ante expected probability of success of a type $G$ project in the absence of screening.

Screening, similarly to monitoring, is nonverifiable. All other assumptions are unchanged. In particular, we maintain that the entrepreneurs can credibly disclose their sources of financing if they are subject to the disclosure law.

\subsection{Monitoring and Screening}

As in the model without screening entrepreneurs have the choice between projects of type $G$ and $B$ and this choice is private information. In the absence of screening, entrepreneurs do not know the quality of projects of type $G$. In this case, the incentive to choose a type $G$ project rather than a type $B$ project is still given by equation (2). When subject to screening, entrepreneurs learn that the quality of their investments is $\bar{G}$, and therefore incentives to choose type $G$ projects require ${ }^{10}$

$$
\left(r-r_{w a c c}\right) b+B>\left(r-r_{w a c c}\right) \bar{g} \Leftrightarrow r_{w a c c}>r-\frac{B}{\Delta_{\max }},
$$

where $\Delta_{\max }=\bar{g}-b$. In order to maintain that moral hazard is pervasive, we impose $\gamma / \bar{g}>r-B / \Delta_{\max }$.

Bankers' incentive to monitor conditional on not screening is still given by equation (3), while if the banker is screening, incentives to monitor require

$$
r_{l} l^{d} \geq \frac{c}{\Delta_{\max }}
$$

We note that screening and entrepreneur adds value if and only if the entrepreneur is choosing a type $G$ project. Therefore, since moral hazard is pervasive, screening could take place only if the banker is monitoring. Screening takes place as follows. The entrepreneur samples a project of type $G$, and the banker incurs a cost $s$ to observe the quality of such investment. If the quality is $\bar{G}$ the screening process terminates, otherwise, the investment is discarded and the entrepreneur will sample another project, and the banker will screen again. Since the probability that the entrepreneur samples a quality $\bar{G}$ is equal to $\lambda$, the expected screening cost per entrepreneur is equal to $\sigma=s / \lambda$. Accordingly, the overall expected return for the banker when screening is $\bar{g} r_{l} l^{d}-c-\sigma$, while if the banker just monitors, the expected return would be $g r_{l} l^{d}-c$. Therefore, the necessary and sufficient condition for bankers to screen is

$$
r_{l} l^{d} \geq \frac{\sigma}{\Delta_{\min }},
$$

\footnotetext{
${ }^{10}$ As it emerges from the following discussion, bankers only select quality $\bar{G}$ when screening. Entrepreneurs run the investments that the bankers are willing to finance; therefore, when subject to screening, they learn that the quality of the investment they are undertaking is $\bar{G}$.
} 
where $\Delta_{\min }=\bar{g}-g$. In order for the banker to have the incentive to screen, the overall promised payment, $r_{l} l^{d}$, must be high enough.

Define $\widehat{\sigma} \equiv c \Delta_{\min } / \Delta$. In all the following analysis we assume $\sigma>\widehat{\sigma}$, in order to allow for the possibility of monitoring without screening to occur in equilibrium. Furthermore, in order to focus only on equilibria where financial exchange takes place, we only consider the case in which $r>(\gamma+c) / g$.

\subsection{Equilibrium analysis}

Definition 1 applies. Financial investors' behavior is still described by equations (6) and (7), where now

$$
\pi_{b}=\max \left(g r_{l}-\frac{c}{l^{d}}, \bar{g} r_{l}-\frac{c+\sigma}{l^{d}}, b r_{l}\right)
$$

to account for the possibility that bankers could screen the quality of financed investment if they wish. Also, note that the expected return to market finance, $E\left(r_{e}\right)$, equals $\bar{g} r_{e}$ if entrepreneurs issuing financial securities are subject to screening.

Similarly, entrepreneurs' demand for finance is still described by equation (8). Moreover, Lemma 1 still applies so that, without disclosure law, entrepreneurs cannot commit to the choice of projects of type $G .{ }^{11}$ As before, it then follows that, without disclosure law, disclosing the amount of bank-financing does not serve as a signal of whether an entrepreneur will be monitored. Therefore, the rate of return to market finance, $r_{e}$, does not depend on the entrepreneur's choice of capital structure. Under these circumstances, entrepreneurs' capital structure decisions are as in the previous model.

Things are different in the presence of the disclosure law, which guarantees the truthfulness of the disclosed information. By demanding (and disclosing) an amount of bank finance, $l^{d}$, greater or equal to $c / \Delta r_{l}$, entrepreneurs would credibly signal that they are subject to monitoring. Entrepreneurs might actually want to demand more bank-finance than $c / \Delta r_{l}$ to induce bankers to screen. Given equation (13), for a banker to be given the incentive to screen, $l^{d} \geq \sigma / \Delta_{\min } r_{l}$ must hold. By disclosing such an amount of bankfinance entrepreneurs would signal to the otherwise uninformed market investors that their project is subject to screening. This would result in cheaper market finance.

Let $r_{e}$ be the return that an entrepreneur with $l^{d} \geq \sigma / \Delta_{\min } r_{l}$ must guarantee to market investors. Then, $r_{e} \bar{g} / g$ would be the return that an entrepreneur with $l^{d} \in$ $\left[c / \Delta r_{l}, \sigma / \Delta_{\min } r_{l}\right)$ should guarantee to market investors, where $\bar{g} / g>1$. This is the case because market investors know that entrepreneur will choose a type $G$ project, but such project will not be subject to screening and accordingly its probability of success is $g$ rather than $\bar{g}$. Moreover, as before, $r_{e} g / b$ is the return that an entrepreneur with $l^{d}<c / \Delta r_{l}$ should guarantee to market investors. Note that, $\sigma>\widehat{\sigma}$ implies $c / \Delta r_{l}<\sigma / \Delta_{\min } r_{l}$.

\footnotetext{
${ }^{11}$ Following the logics of the proof of lemma 1 it can be easily verified that imposing $\gamma / \bar{g}>r-B / \Delta_{\max }$ is sufficient for entrepreneurs to have a strong incentive to choose type $B$ projects in any equilibrium with financial exchange.
} 
Correspondingly, the average cost of capital faced by an entrepreneur is

$$
r_{\text {wacc }}=\left\{\begin{array}{ll}
r_{l} l^{d}+\left(1-l^{d}\right) r_{e} & \text { if } l^{d} \geq \frac{\sigma}{\Delta \min r_{l}} \\
r_{l} l^{d}+\left(1-l^{d}\right) r_{e} \bar{g} / g & \text { if } l^{d} \in\left[\frac{c}{\Delta r_{l}}, \frac{\sigma}{\Delta_{\min } r_{l}}\right) . \\
r_{l} l^{d}+\left(1-l^{d}\right) r_{e} \bar{g} / b & \text { if } l^{d}<\frac{c}{\Delta r_{l}}
\end{array} .\right.
$$

Then, entrepreneurial demand of market-finance is as follows

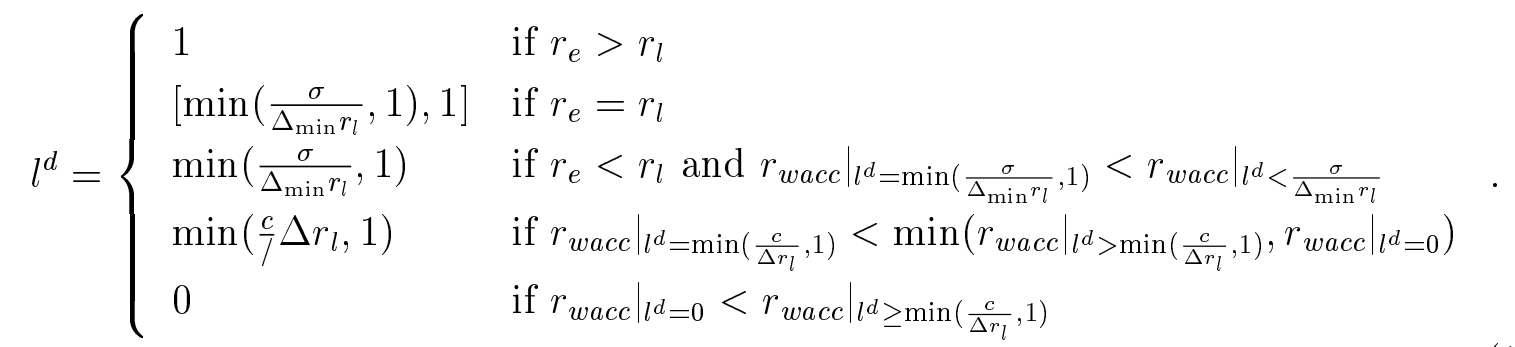

Note that, similarly to the previous model, a necessary condition for entrepreneurs to demand less bank-finance than $c / \Delta r_{l}$ is $r_{l}<r_{e} g / b$. Under this scenario, when demanding less bank-finance than $c / \Delta r_{l}$, the optimal strategy is to set $l^{d}=0$.

Having analyzed individual behavior, we now proceed to characterize the equilibrium. In principle, the equilibrium can take two forms: a. Pooling, with no screening, in which case investment types $\underline{G}$ and $\bar{G}$ are pooled together and financed so that the probability of success of financed investments equals $g$, and; $b$. Separating, in which investments of type $\bar{G}$ are separated from type $\underline{G}$ investments by means of the screening process, and only type $\bar{G}$ are financed, so that the probability of success of financed projects is $\bar{g}$.

We analyze first the equilibrium in the absence of disclosure law. Without disclosure law, information on whether entrepreneurs are monitored and their projects are screened remains private. Accordingly,

Lemma 2 Given $r>(\gamma+c) / g$ ) and $r \neq \sigma / \Delta_{\min }$, without the disclosure law the equilibrium is unique and characterized as follows:

$i$. The amount of financed investment is $S$ and bank-finance is the only form of financing: $l^{d *}=1 ; r_{l}^{*}=r$;

ii. The equilibrium involves pooling and no screening if $r<\sigma / \Delta_{\min }$ and separation through screening otherwise.

Proof. See Appendix.

Screening is (strictly) efficient if and only if the expected productivity gains it induces, $\Delta_{\min } r$, (strictly) exceed the expected screening cost, $\sigma$, i.e. if and only if $r \geq(>) \sigma / \Delta_{\min }$. In the absence of disclosure law, bankers are the only suppliers of finance. Given $N>$ $S, r_{l}=r$ holds and bankers appropriate all the surplus generated by entrepreneurs' investments net of monitoring and screening costs. Under these circumstances, bankers 
fully internalize the benefits from screening, and this is why, as described in Lemma 2 they always undertake the efficient level of screening.

Differently, in the presence of the disclosure law, market investors benefit from screening, as screening results in an increase in the probability associated with the promised return $r_{e}$, without incurring any of the costs. As we show next, this turns out to have crucial implications with respect to the efficiency of screening in the prevailing equilibrium.

\subsubsection{Pooling equilibrium}

In a pooling equilibrium, banks perform no screening, and both quality $\bar{G}$ and $\underline{G}$ projects are financed, such that ex-post, a fraction $g$ of the investment projects is successful and the overall welfare gain generated by financial exchange is $g r-c$.

Lemma 3 The pooling equilibrium, if it exists, is unique and is characterized as follows:

i. The aggregate amount of financed investment is $S, l^{d *}=\frac{c b}{\Delta g r_{e}^{*}}<1, r_{e}^{*}=r-\frac{c}{g}$ and $r_{l}^{*}=\left(r-\frac{c}{g}\right) \frac{g}{b}$.

Proof. See appendix.

Crucially, the existence of a pooling equilibrium requires a further condition to be satisfied. Given $r_{l}^{*}, r_{e}^{*}$ and $l^{d *}$, entrepreneurs should not have the incentive to deviate and increase their demand of bank-finance from $l^{d}$ to $l^{\prime}$, in order to induce bankers to screen, where based on equation (13),

$$
l^{\prime}=\frac{\sigma}{\Delta_{\min } r_{l}^{*}}
$$

Note that such deviation is feasible if and only if, given $r_{l}^{*}, l^{\prime} \leq 1$. By substituting in the value of $r_{l}^{*}$ one can verify that $l^{\prime}<1$ holds for $r \geq \sigma / \Delta_{\min }$, i.e. for those values of $r$ such that screening would be efficient. ${ }^{12}$

Given $r_{e}^{*}$, the return on market-finance that an entrepreneur subject to screening should promise market investors is $g r_{e}^{*} / \bar{g}$. Hence, for an entrepreneur who deviates from $l^{d *}$ to $l^{\prime}$

$$
r_{w a c c}^{\prime} l_{l^{d}=l^{\prime}}=\frac{\sigma}{\Delta_{\min }}+\left(1-l^{\prime}\right) \frac{r_{e}^{*} g}{\bar{g}} .
$$

Then, the following result holds

Lemma 4 Given $\sigma>\widehat{\sigma}$, the pooling equilibrium exists if and only if $r \leq \bar{r} \equiv \frac{\sigma}{\Delta_{\min }} \frac{\Delta_{\max }}{\Delta_{\min }}-$ $\left.\frac{c}{\Delta_{\min }}\right)$.

Proof. See Appendix.

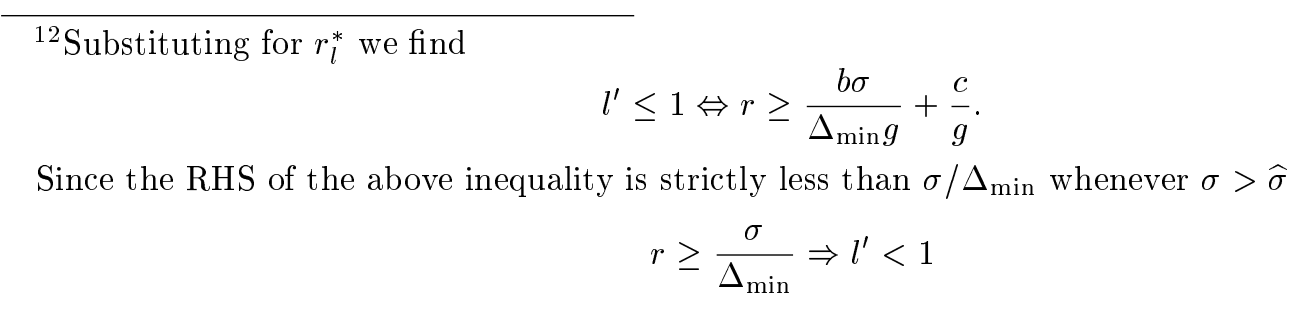

follows. 


\subsubsection{Separating equilibrium}

In a separating equilibrium, only quality $\bar{G}$ investments are financed. The expected profit of entrepreneurs is $\bar{g}\left(r-r_{\text {wacc }}\right)$ and the expected profits of bankers are $\bar{g} l^{d} r_{l}-c-\sigma$. Define, $\theta=c / \sigma$. Then,

Lemma 5 A separating equilibrium does not exist if $r<\sigma / \Delta_{\min }$. If the reverse inequality holds, the separating equilibrium, if it exists, is unique and it is characterized as follows

i. The mass of financed investment is $S$. If $r=\sigma / \Delta_{\min }, l^{d *}=1$ and $r_{i} *=r$. If $r>\sigma / \Delta_{\min }, l^{d *}=\frac{\sigma\left(g-\theta \Delta_{\min }\right)}{\bar{g} \Delta_{\min } r_{e}^{*}}, r_{e}^{*}=r-\frac{c+\sigma}{\bar{g}}, r_{l}^{*}=\frac{\bar{g} r_{e}^{S}}{g-\Delta_{\min } \theta}$.

Proof. See Appendix.

In order for a screening equilibrium to exist, entrepreneurs need to have no incentive to reduce their demand of bank-finance from $l^{d *}$ to $l^{\prime \prime}$ in order to give banks incentives just enough to provide monitoring and no screening, where given equation (4), and $r_{l}^{*}$

$$
l^{\prime \prime}=\frac{c}{\Delta r_{l}^{*}},
$$

If an entrepreneur deviates and demands $l^{\prime \prime}$ units of bank-finance, thereby being not subject to screening anymore, the cost of direct finance goes up to $\bar{g} r_{e}^{*} / g{ }^{13}$ Accordingly, the weighted cost of capital associated with such deviation will be

$$
r_{w a c c}^{\prime \prime}=\frac{c}{\Delta}+\left(1-l^{\prime \prime}\right) r_{e}^{*} \frac{\bar{g}}{g}
$$

It then follows,

Lemma 6 Given $\sigma>\widehat{\sigma}$, the separating equilibrium exists if and only if $r \geq \underline{r} \equiv \frac{\sigma}{\Delta_{\min }}+$ $\left.\frac{c}{\Delta_{\min }}-\frac{c}{\Delta} \theta\right)$.

Proof. See Appendix.

\subsection{Prevailing equilibrium}

The ultimate objective of our analysis is to determine whether the prevailing equilibrium would involve the efficient level of screening. As discussed earlier, screening is efficient if and only if $r>\sigma / \Delta_{\min }$. Accordingly, on the basis of lemmata (4) and (6) we are able state the following

Proposition 2 Given $r>(c+\gamma) / g$ and $\sigma>\widehat{\sigma}$ :

1. For $r \in\left[\frac{\sigma}{\Delta_{\min }}, \underline{r}\right)$ the pooling equilibrium is the unique equilibrium, while separation through screening would be efficient;

\footnotetext{
${ }^{13}$ By observing the amount of bank-finance, $l$, , market investors who invest in financial securities know that the entrepreneurs' investments are not going to be screened.
} 
2. For $r \in[\underline{r}, \bar{r}]$ pooling and screening equilibria coexist and screening is efficient;

3. For all other values of $r$ there is a unique equilibrium. This involves separation through screening whenever screening is efficient(i.e. for $r>\bar{r}$ ) and pooling otherwise (i.e. for $r<\sigma / \Delta_{\min }$ ).

Proof. See Appendix.

Proposition 2 summarizes our results. For values of the screening cost sufficiently high, i.e. $\sigma>\widehat{\sigma}$, and if the return to investment in the case of success is not sufficiently high a pooling equilibrium where bankers undertake no screening can prevail even though screening would contribute a positive NPV in expected terms. Whenever this is the case, the introduction of a financial market characterized by a disclosure law implies a net allocative efficiency loss as bankers loose the incentive to screen. This would result in investment generating a lower expected net present value than would have been otherwise.

The possibility of the economy being characterized by an inefficiently low level of screening as a consequence of the development of market-finance following the introduction of the disclosure law, stems from the crucial observation that market investors benefit from the gains from screening without incurring any of the associated costs.

\section{$4 \quad$ Financial structure and economic growth}

The above results are incorporated in a simple OLG model to derive their implications for the relationship between financial structure and growth.

We consider an economy populated by a continuum of size $N$ of two periods living identical entrepreneurs and overlapping generations of size $S$ of two-periods living identical financial investors. All agents are risk-neutral and derive utility from consumption in their second period of life only. Financial investors are endowed with one unit of labor that they supply to firms in exchange for a salary $w_{t}$ when young. They save the resulting labor income either by investing in a safe asset yielding a return $\gamma$ or by financing entrepreneurs' activity. Entrepreneurs have no endowment of labor and are the only ones able to run firm production. ${ }^{14}$ Each entrepreneur can run at most one firm.

Firms are competitive and produce according to $Y_{t}=v \psi K_{t}^{\alpha} N_{t}^{1-\alpha} A_{t}$, where $Y_{t}$ is output per firm, $K_{t}$ is capital per firm, $N_{t}$ is labor per-firm, $\psi$ and $\alpha$ are parameters greater than zero, $v$ is a random variable that takes value 1 in the case of success and 0 in the case of failure, and $A_{t}$ is a learning by doing externality, with $A_{t}=k_{t}^{\alpha}$, where $k_{t}=K_{t} / N_{t}$. Full capital depreciation is assumed, so that investment at time $t$ equals next period capital, $K_{t+1}$. The probability of success at time $t+1$ depends on the quality of the investment in physical capital, $K_{t+1}$, undertaken at time $t$.

\footnotetext{
${ }^{14}$ Note that the assumption that entrepreneurs have no endowments is made only to simplify the exposition.
} 
Each firm is operated by an entrepreneur. Entrepreneurs have the same role of entrepreneurs in the models described in the previous section: they decide whether to undertake project of type $G$ or type $B$, where a project is now of variable size. If the firm investment in physical capital is of type $i$, where $i=G, B$ the probability of success is $j=g, b$. Moreover, following previous analysis, type $G$ investments are either of quality $\bar{G}$ or quality $\underline{G}$. In the first case, the probability of success is $\bar{g}$, while in the second case it would be $\underline{g}$, where we maintain $\bar{g}>\underline{g}$. As before, $g=\lambda \bar{g}+(1-\lambda) \underline{g}$ represents the expected value of the probability of a type $G$ investment of unknown quality.

As in the previous analysis, entrepreneurs' choice of projects' type is private information. Financial investors can observe it by incurring a monitoring cost $c$ per unit of capital, so that the total cost of monitoring a firm investing an amount $K_{t+1}$ is $c K_{t+1}$. Moreover, equivalently to section 3 , entrepreneurs do not know the quality of type $G$ projects. Financial investors can observe such quality by incurring a screening cost $\sigma K_{t+1}$, where we recall that $\sigma$ is the expected screening cost per unit of investment.

Finally, both screening and monitoring costs are measured in terms of forgone return to capital.

\subsection{Monitoring and screening}

As in the models discussed in previous sections entrepreneurs derive private benefits $B$ per unit of firm's investment when choosing projects of type $B$ while they derive none from projects of type $G$. Consider a firm investing an amount $K_{t+1}$, financed by an amount $L_{t}^{d}$ of bank-finance and an amount $E_{t}^{d}$ of market-finance, where $K_{t+1}=E_{t}^{d}+L_{t}^{d}$ holds. Then wacc faced by the firm is

$$
r_{w a c c, t+1}=r_{l, t+1} l_{t}^{d}+r_{e, t+1} e_{t}
$$

where, $l_{t+1}^{d}=L_{t}^{d} / K_{t+1}$ and $e_{t}^{d}=E_{t}^{d} / K_{t+1}$ measures the relative contribution of bankfinance and market-finance to the overall financing of the firm. Note that the only difference between the above expression of the wacc and equation (1) is that now all variables carry a time subscript.

If an entrepreneur decides that firm's investment should be of type $G$, her expected profits would be $g K_{t+1}\left(r_{t+1}-r_{\text {wacc }, t+1}\right)$, where $r_{t+1}$ is the return to physical capital to be determined in equilibrium. Otherwise, if the selected investment is of type $B$, her expected profit would be $b K_{t+1}\left(r-r_{w a c c, t+1}\right)+B K_{t+1}$. Accordingly, moral hazard occurs according to (2), where $r_{w a c c, t+1}$ is now replaced by $r_{w a c c, t+1}$ on the right hand side of the inequality. We maintain $\left(\gamma / \bar{g}>r_{t+1}-B / \Delta_{\max }\right)$ so that that moral hazard is pervasive, .

Bankers' behavior is the as in the previous model. Let $L^{d}$ be the amount of bankfinance demanded by an entrepreneur. Without screening, a banker supplying a loan $L^{d}$ has the incentive to monitor the entrepreneur if

$$
g r_{l, t+1} L_{t}^{d}-c K_{t+1} \geq b g r_{l, t+1} L_{t}^{d} \Leftrightarrow l_{t}^{d} r_{l, t+1} \geq \frac{c}{\Delta}
$$


which is equivalent to (4). Also, in the presence of screening, incentives to monitor require

$$
L_{t}^{d} r_{l, t+1} \geq \frac{c K_{t+1}}{\Delta_{\max }} \Leftrightarrow l_{t}^{d} r_{l, t+1} \geq \frac{c}{\Delta_{\max }}
$$

Similarly, incentives to screen require

$$
L_{t}^{d} r_{l, t+1} \geq \frac{\sigma K_{t+1}}{\Delta_{\min }} \Leftrightarrow l_{t}^{d} r_{l, t+1} \geq \frac{\sigma}{\Delta_{\min }} .
$$

Note that the equivalents of (23) and (24) in the model with unit size investment discussed in the previous section are given by (12) and (13).

We maintain that previous assumption that $\sigma>\widehat{\sigma}$, where we recall that $\widehat{\sigma}=\Delta_{\min } c / \Delta$. Furthermore, we focus on the case in which, $r_{t+1}>(\gamma+c) / g$, so that the competitive equilibrium always involve financial exchange. The sufficient condition on $\alpha$ and $\psi$ for such inequality to hold will become clear later on in the discussion.

\subsection{Macroeconomic Equilibrium analysis}

Definition 2 A competitive (macroeconomic) equilibrium with financial exchange is a sequence of $K_{t+1}, r_{e, t}, r_{l, t}, w_{t}$, such that, for all $t$

i. Given the returns, financial investors and entrepreneurs act optimally;

ii. $K_{t+1}=S w_{t} / N$;

iii. $r_{t}=\alpha \psi ; w_{t}=(1-\alpha) \psi k_{t}$;

iv. The markets for bank-finance, market-finance and labor clear.

Condition (ii) is a market clearing condition that states that firm-level investment $K_{t+1}$ should equal aggregate savings, $w_{t} S$, divided by the number of operating firms $N$. It follows directly from the assumption that the profit-maximizing firms are price takers, that

$$
\begin{array}{r}
r_{t}=\alpha \psi k_{t}^{\alpha} A_{t} \\
w_{t}(1-\alpha) \psi k_{t}^{\alpha} A_{t} .
\end{array}
$$

In equilibrium $A_{t}=k_{t}^{1-\alpha}$, which implies $r_{t}=\alpha \psi$ and $w_{t}=(1-\alpha) \psi k_{t}$ (condition iii). Note that, at any time $t$, the fraction of successful firms is $i$, where $i=g$ if firms' investment is not subject to screening, and $i=\bar{g}$ otherwise, so that the mass of successful firms is $i N$. Since total labor supply is $S, S / N i$ is the amount of labor per firm. Therefore, $k_{t}=K_{t} N i / S$. Finally, condition $\mathrm{v}$ states that in equilibrium the markets for bank and market finance as well as the market for labor should clear.

Given $r_{t+1}$, individual financial decisions of both financial investors and entrepreneurs are exactly the same as in the model with unit size investment, so that the analysis of section 3.2 applies. The only notable difference concerns the aggregate demand for financial 
resources, which in equilibrium tends to infinity, rather than to $N$, when $r_{w a c c, t+1}<r_{t+1}$, and correspondingly, it is infinitely elastic between 0 and $\infty$ rather than between 0 and $N$ for $r_{\text {wacc, } t+1}$. Still, equilibrium demand is 0 for $r_{t+1}>r_{w a c c, t+1}$.

Having analyzed individual behavior, we briefly discuss the equilibrium with financial exchange and characterize its properties in the absence and presence of the disclosure law on the basis of the results formally derived in sections 2 and 3.

First of all, we observe that as in the model with unit size investment, for an equilibrium with financial exchange to exist, the equilibrium return to capital in case of financial exchange, $\alpha \psi$, must exceed $(\gamma+c) / g \cdot{ }^{15}$ Furthermore, since the demand for financial resources tends to $\infty$ for $r_{w a c c, t+1}<r_{t+1}$, in any equilibrium with financial exchange $r_{w a c c, t+1}=r_{t+1}$ : financial investors still appropriate all the return to capital.

In the absence of the disclosure law, Lemma 2 applies: bank-finance is the only source of finance and screening still occurs if and only if $r_{t}>\sigma / \Delta_{\min }$ i.e. if and only if $\alpha \psi>\sigma / \Delta_{\min }$, where we are imposing the equilibrium value of $r_{t}=\alpha \psi$. Following the definition of macroeconomic equilibrium, in the absence of screening, $w_{t}=(1-\alpha) g \psi k_{t}$, with $k_{t}=$ $K_{t} g N / S$. Correspondingly, given $K_{t+1}=S w_{t} / N$, aggregate product at time $t+1$, gross of monitoring costs, is $N g Y_{t}(1-\alpha)$. Monitoring costs are measured in units of forgone return to capital. Accordingly, aggregate monitoring costs amount to $c(1-\alpha) Y_{t} N g$. Therefore, when screening does not take place, the growth rate of the economy is

$$
\operatorname{Growth}_{t}^{M}=(g \psi-c)(1-\alpha)-1 \text {. }
$$

Noting that in the presence of screening $\bar{g} N$ firms are successful in each period, by applying the above procedure the growth rate in the case of screening is found to be

$$
\text { Growth } h_{t}^{S}=(\bar{g} \psi-c-\sigma)(1-\alpha)-1
$$

Comparison of equations (27) and (28) suggests that screening results in a higher growth rate whenever $\psi \geq \sigma / \Delta_{\min }$. Yet, as discussed above, screening takes place if and only if $\alpha \psi \geq \sigma / \Delta_{\min }$. As $\alpha<1$ holds, this implies the possibility that even when bankers are the only providers of finance, the level of screening can be inefficiently low. This effect, which is novel with respect to the model with unit investment and no growth, is due to the fact that differently from that model, even when the bankers are the only suppliers of finance, they do not appropriate the overall return that physical investment generates; part of it is in fact appropriate by workers, who provide the other input necessary for production, namely labor.

As for the equilibrium in the presence of disclosure law, the results derived in the model with unit size investment presented in Lemmata 3-6 hold. Hence, the prevailing equilibrium is as described in proposition 2, where $r$ is now to be replaced by $r_{t}$, with $r_{t}=\alpha \psi$ according to definition 2. Therefore, we derive the following

\footnotetext{
${ }^{15}$ If not, financial investors would prefer to invest in the safe asset, which will lead to an equilibrium with no production.
} 
Proposition 3 The development of market-finance following the introduction of the disclosure law has ambiguous effects on economic growth:

i. For $\alpha \psi \in\left(\frac{\sigma}{\Delta_{\min }}, \underline{r}\right)$ the effect is negative;

ii. For $\alpha \psi \in[\underline{r}, \bar{r}]$ there effect is either nil or negative;

iii. For all other values of $\alpha \psi$ the effect is nil.

The above proposition follows directly from Proposition 2, where $r$ is being replaced by $\alpha \psi$ and thus it does not require a formal proof. Let us consider an economy without disclosure law: assuming $\alpha \psi \geq \sigma / \Delta_{\min }$, bankers, who are the only providers of finance, perform screening which results in maximum growth at the value given by equation (28). Assume the disclosure law is introduced. Then, in the resulting equilibrium, external finance will be provided both by bankers and market investors. In case $(i)$, the return to capital is so low that the resulting equilibrium will not involve screening, and the growth rate would be given by equation (27). This holds even when screening would lead to a higher growth rate, which happens if the return to capital exceeds $\sigma / \Delta_{\min }$. In this case, the development of market-finance, by inhibiting the screening role of bankers, has a negative an adverse effect on growth .

For intermediate values of the return to capital, case $(i i)$, the equilibrium outcome in terms of level of screening is uncertain, the financial sector can end up either a pooling or in a screening equilibrium. In the first instance, provided that $\alpha \psi>\sigma / \Delta_{\min }$, the development of market-finance would have an adverse effect on growth, while in the second instance it would have none.

Finally, for high values of the return to capital, case ( $i i i)$, the development of marketfinance has no consequences on the level of screening undertaken by bankers. Accordingly, there are no consequences for economic growth.

\section{Empirical Method, Data and Results}

Our analysis implies that, other things being equal, the shift from a system in which there is only bank-finance to a system in which bank-finance and market-finance co-exist influences the growth process. The development of market-finance spurred by the introduction of a disclosure law regarding the sources of financing of entrepreneurs might affect negatively the growth process by influencing the screening activity performed by bankers. In this section, we test the presence of such interaction using a standard cross-section growth model and using Demirguc-Kunt and Levine (2001) dataset, the basis on which the 'financial services view' receives its empirical support.

In order to assess the growth impact of the interaction between bank and market finance, we would ideally like to have a broad measure of these types of finance. However, due to data limitations, it is not feasible to construct for a large list of countries a broad 
indicator of market-finance which encompasses all types of financial markets. Following the empirical literature, we rely on stock market development indicators to proxy for the importance of market-finance. In our model, entrepreneurs wishing to raise market finance must comply with disclosure law. Similarly, before a company is able to raise finance in the stock market, it has to meet some listing requirements and disclose information to market participants according to some specified laws. To gauge the importance of bank-finance, we rely on traditional banking development indicators which measure the size of banking credit to GDP. Thus, to test the implication of the model that the interaction between the various components of the financial systems may matter for growth, we examine whether the interaction between bank and stock market development has a significant impact on long-run growth.

We estimate a cross-section growth model similar to that of King and Levine (1993) and Barro and Sala-i-Martin (1992). The real growth of per capita income is regressed on a vector of country controls, measures of banking and stock market development, and an additional interaction term between the latter two variables. Thus, we modify the standard growth regression as follows

$$
\text { Growt }_{i}=a_{0}+\sum_{i} \alpha_{i} \text { Country }_{i}+\delta_{1} \text { Bank }_{i}+\delta_{2} \text { Tor }_{i}+\delta_{3} \text { Interact }+e_{i},
$$

where Growth is the long-run growth rate of real per capita GDP averaged over 1980-1995; Bank is the level of banking development measured by the claims on private sector by deposit money banks as a share of GDP over 1980-1995; Tor is the stock market turnover ratio measured over 1980-1995; Interact is an interactive term between Bank and Tor, and Country is a vector of country controls usually used in cross-section regressions to control for other potential determinants of cross-country growth rates (see for instance Barro and Sala-i-Martin, 1992; Beck and Levine (2002)). In the base regression, we include initial income per capita measured by the logarithm of real GDP per capita in 1980 to control for the convergence effect. For robustness, the list of country control is later widened to include initial human capital measured by the average school years in the population over 25 in 1980; an indicator of government size measured by government expenditure as share of GDP; the inflation rate calculated as log difference of CPI averaged; trade openness measured by real exports and imports as share of real GDP and the black market is measured by the black market premium. All these variables (except for initial human capital) are averages over the period 1980-1995.

We use Demirguc-Kunt and Levine (2001) dataset, ${ }^{16}$ which covers more than 100 countries over the period 1980-1995. The use of this dataset generates at least two main benefits. First, it allows us to compare our results with existing studies dealing with the issue of financial structure and economic growth, most of which make use of this dataset.

\footnotetext{
${ }^{16}$ For a detailed description of the dataset, definitions and sources, see Demirguc-Kunt and Levine (2001).
} 
Second, the list of variables included is quite comprehensive allowing us to construct a large number of instruments to test for the endogeneity of Bank, Tor and Interact and carry the appropriate tests on suitability of these instruments.

The interaction term used in the empirical model is an interaction between two continuous variables. What the interaction term signifies in equation (1) requires some further explanation as this type of interaction is not widely used in the literature (Cohen et al., 2003, Jaccard and Turrisi, 2003). Given interact $=$ Bank $\times$ Tor the regression model (29) can be written as:

$$
\text { Growth }=a_{0}+\left(\delta_{1}+\delta_{3} \text { Tor }\right) \text { Bank }+\delta_{2} \text { Tor }+e
$$

or

$$
\text { Growth }=a_{0}+\left(\delta_{2}+\delta_{3} \text { bank }\right) \text { Tor }+\delta_{1} \text { Bank }+e,
$$

where we neglect the vector of controls for simplicity.

In equation (29) the estimated coefficients on Bank and Tor reflect conditional relationships. In other words, $\delta_{1}$ measures the effect of Bank on Growth when Tor is zero, while $\delta_{2}$ measures the effect of Tor on Growth when Bank is zero. Effects can be made more interpretable by centering variables around the mean. Accordingly, $\delta_{1}$ would measure the effect of Bank on Growth when Tor takes a mean value, while $\delta_{2}$ would measure the effect of Tor on Growth when Bank takes a mean value.

According to equations (30) and (31), the total effect of Bank or Tor on Growth depends on the estimated coefficient of the interaction term. For instance, in equation (31), a negative value for the effect of the interaction term indicates that the higher the level of stock market development measured by it turnover ratio, the lower (or less positive) is the effect of banking development on growth. Also note that the slope of the regression of Growth on Bank (usually known as the simple slope) depends upon the particular value that Tor takes. This allows us to interpret the results in a more informative way. Specifically, we can choose a grid of values of Tor, substitute them into the estimated equation and generate the correspondent series of simple slopes of Growth on Bank at different values of Tor. This allows us to explore the effect of banking development on growth at different levels of stock market development. ${ }^{17}$

Testing whether the simple slopes of the regression of Growth on Bank are different at different values of Tor is identical to the t-test used for the significance of coefficient of $\delta_{3}$ in the overall regression (Cohen et al., 2003). ${ }^{18}$

\footnotetext{
${ }^{17}$ To test whether the slope of the regression at different values of Tor is significant, we use the values from the variance covariance matrix of the regression coefficients. Specifically, the standard error of the regression coefficient for Bank is given by $S_{\delta_{1}}=\sqrt{s_{11}+2 \operatorname{Tor}_{13}+\text { Tor }^{2} s_{33}}$ where $s_{11}$ and $s_{33}$ are the variances of Bank and Interact respectively and $s_{13}$ is covariance between Bank and Interact all taken from the sample estimate of the variance covariance matrix. The test of the simple slope is a $t$-test with $t$ equal to the simple slope divided by its standard error, with $N-k-1$ degrees of freedom, where $N$ is the sample size and $k$ is the number of independent variables including the interaction term.

${ }^{18}$ For instance, consider two value of Tor, call them $\operatorname{Tor}_{H}$ and $\operatorname{Tor}_{L}$. The simple slopes in question will
} 


\subsection{Empirical results}

Columns 1 and 2 in Table 1 report the results of the base OLS regression with and without centering the variables. The overall regression results suggest that highly developed countries tend to grow slower implying a convergence effect; that higher level of banking development is associated with higher per capita growth rates; and that higher turnover ratio of stock markets are associated with higher per capita growth rates. Interestingly, the coefficient on the interactive term $\left(\delta_{3}\right)$ is negative and highly significant indicating the existence of interaction effect between stock market and banking development. Specifically, the significant negative coefficient on the term Interact implies that the higher the level of stock market development, the lower (or less positive) is the effect of banking development on growth. Similarly, it also indicates that the higher the level of banking development, the lower (the less positive) is the effect of stock market on growth. The fact that the estimated value of $\delta_{3}$ is significantly different from zero might be reflecting a non-linearity in the finance-growth relationship, rather than an interaction effect. Both banking depth and stock market development are largely driven by a set of other variables and are also highly correlated across countries. If there is diminishing growth returns to financial development generally, then any second order term including the interaction term will have a negative coefficient. To account for this possibility, we include in Column 3 , the regression results with the other second-order terms $\left(B a n k^{2}\right.$ and $\left.\operatorname{Tor}^{2}\right)$. However, as can be seen from Table 1, the interaction term retains its high significance while both Bank $^{2}$ and Tor $^{2}$ are not significant at the conventional levels.

To explore further the impact of the interaction effect, Figure 2 plots the growth impact of banking depth against the level of stock market development based on the results of Column 2 in Table 1. As can be seen from this figure, as the level of Tor increases, the growth impact of Bank becomes less positive and at two-standard deviations above the mean the impact of Bank and Growth turns negative though the estimated coefficient of Growth on Bank is not significant at the conventional level. ${ }^{19}$

\subsection{Robustness Tests}

Our results are robust to a number of sensitivity checks. First, the main conclusions are not sensitive to the inclusion of a wide list of country controls. Column 1 of Table 2 reports the regression results, conditioning on trade openness, government size, the inflation rate, the black market premium, the initial level of real income per capita and initial level of be $\delta_{2}+\delta_{3} \operatorname{Tor}_{H}$ and $\delta_{1}+\delta_{3}$ Tor $_{L}$. The $t$-test of the difference between the slopes in this example would be given by

$$
t=\frac{\left(\text { Tor }_{H}-\text { Tor }_{L}\right) \delta_{3}}{\sqrt{\left(\text { Tor }_{H}-\text { Tor }_{L}\right)^{2} s_{33}}}=\frac{\delta_{3}}{\sqrt{s 33}}
$$

${ }^{19}$ At Tor $=0.99$, i.e. at two standard deviation above the mean, the estimated coefficient of Growth on Bank is -0.03 with standard error of 1.23 . 
schooling. As can be seen from the table, the estimated coefficients on Bank and Tor are positive and significant while the estimated coefficient on interactive term is negative and retains its significance at the $1 \%$ level. The only minor difference from the previous result is that the estimated coefficient on banking development decreases in size, but is still significant at the $10 \%$ level.

In addition to $O L S$, we use instrumental variables $(I V)$ estimation to control for potential simultaneity bias and reverse causality from growth rates to bank and stock market development. The following set of instruments is used to extract the exogenous component of banking and stock development. First, we use the legal origin of each country (French, English, German or Scandinavian) as instruments. Legal origins can explain differences in legal codes and the efficiency in which laws are enforced. Second, we use creditor rights index which measures the degree of that legal codes support secured creditors in case of reorganization or liquidation of a company. Third, we use shareholder rights index which measures the degree of support the legal system provides for minority shareholders against managers or dominant shareholders. Fourth, we include instruments that measure the quality of a country's accounting standards. As argued by La Porta et al. (1998), accounting play an important role in corporate governance, in establishing contracts between managers and investors, and interpreting company disclosures. Finally, we use the law of law which is a measure of the law and order tradition of a country and the efficiency and quality of enforcement of investors' rights. ${ }^{20}$ La Porta et al. (1998) argue that the legal origins and legal codes supporting creditors and shareholders were determined centuries earlier and hence can be treated as exogenously for the purpose of this analysis.

We report the Hansen test for over-identifying restrictions (Davidson and McKinnon, 1993; Baum, Schaffer, and Stillman, 2002). The Hansen test of over-identifying restrictions tests the validity of the instruments used. The hypothesis being tested is that the instruments used are uncorrelated to the residuals. If we are unable to reject the null hypothesis, then the instruments used are appropriate. As can be seen from Column B Table 2, the results are robust to the use of IV technique. Banking and stock market development enter with significant positive coefficients whereas the estimated coefficient on the interactive term is negative and highly significant. One main difference is that the size of estimated coefficients is much larger than in previous regressions. This result however may be driven by the large reduction in the sample size from 71 to 44 observations and the dominance of high income countries with better data availability in the sample. Hence, the IV results should be treated with caution. As to the validity of the instruments, the Hansen test is unable to reject the null hypothesis indicating that the instruments used are valid i.e. they are not correlated with the error term. In Column C Table 3, we use the IV with the full conditioning set of country controls. The results do not change much,

\footnotetext{
${ }^{20}$ For a detailed description of each of these instruments see La Porta et al. (1998).
} 
except that the size on the estimated coefficients on Bank, Tor and Interact decrease in size.

\section{Conclusion}

Although the growth-finance nexus has been heavily researched both at the theoretical and empirical level, the study of the relationship between financial structure and long run economic growth has so far received much less attention.

This paper analyzes the interaction between market and bank-finance in the context of a model characterized by moral hazard and imperfect information about the quality of investment. We show that the establishment of a financial market where entrepreneurs wishing to raise finance are subject to disclosure law regarding their capital structure might undermine financial institutions' incentive to screen, even when screen would have been efficient. Using this result we also show that the change from a bank-based financial system to a system in which market-finance and bank-finance coexist may impact upon long-run growth. This is contrary to the view which claims that higher financial development, regardless of its source, is always beneficial for economic growth.

Using Demirguc-Kunt and Levine (2001) cross-country dataset and modifying the standard growth regression to include an interaction between stock market and bank development, we find evidence which is consistent with our model. Specifically, we find a significant strongly negative interaction effect implying that at higher levels of stock market development, the contribution of bank development to long run growth becomes less positive. These results offer a new perspective on the 'financial structure and growth' debate. They also have important policy implications, especially for developing and emerging countries which in the last two decades with varying degrees of success have aimed at introducing and/or reforming their stock markets. If competition from stock market undermines the role of bank and leads to disintermediation, then efforts directed establishing a stock-market bank based system may not achieve its intended objectives. 


\section{References}

[1] Allen, F., and D. Gale. 1997. Financial markets, intermediaries and intertemporal smoothing. Journal of Political Economy, 105, 523-546.

[2] Barro, R., X. Sala-i-Martin (1992) Convergence. Journal of Political Economy, 100, 223-251.

[3] Baum, C. F., Schaffer M. E. , and S. Stillman, 2002. Instrumental variables and GMM: Estimation and testing. Boston College Working Papers in Economics 545.

[4] Beck, T. and R. Levine, 2002. Industry growth and capital allocation: Does having a market or bank based system matter? Journal of Financial Economics, 64, 147-180.

[5] Bencivenga, V.R. and B. D. Smith, 1991. Financial Intermediation and Endogenous growth. The Review of Economic Studies, 58, 195-209.

[6] Christopoulos, D.K., E. G. Tsionas. 2004. Financial development and economic growth: Evidence from panel unit root and cointegration tests. Journal of Development Economics, $73,55-74$.

[7] Cohen, J., Cohen, P., West, S., and Aiken, L., 2003. Applied multiple regression/correlation analysis for the behavioral sciences. 3rd Ed. Hillsdale, NJ: Lawrence Erlbaum Associates.

[8] Davidson, R. \& J.G. MacKinnon (1993) Estimation and inference in Econometrics. New York: Cambridge University Press.

[9] Demirguc-Kunt, and, Levine, 2001. Financial Structure and Economic Growth: A cross-Country Comparison of Banks, Markets, and Development. MIT press, Cambridge, MA.

[10] Deidda, L., and B. Fattouh, 2002. Non linearity between finance and growth. Economics Letters, 74, 339-345.

[11] Dolar, V., and C. Meh, 2002. Financial structure and economic Growth: A nontechnical survey. Bank of Canada WP N. 2002/24.

[12] Greenwood, J. and B. Jovanovic, 1990. Financial development, growth and the distribution of income. Journal of Political Economy, 98, 1076-1107.

[13] Harris, R. D. F., 1997. Stock market and development: A re-assessment. European Economic Review, 41, 139-46.

[14] Holmstrom, B., and J. Tirole, 1997. Financial intermediation, loanable funds, and the real sector. Quarterly Journal of Economics. 664-690. 
[15] King, R., and Levine, 1993. Finance and Growh: Schumpeter might be right. Quarterly Journal of Economics, 108, 717-37.

[16] Jaccard, J., and R. Turrisi, 2003. Interaction effects in multiple regression. Sage University Paper series on Quantitative Applications in the Social Sciences, 07-072. Newbury Park, CA: Sage.

[17] Levine, R. 1997. Financial development and growth: Views and agenda. Journal of Economic Literature, 35, 688-726.

[18] Levine, R. 2002, Bank-based or market-based financial systems: Which is better? Journal of Financial Intermediation, 11(4), 398-428.

[19] La Porta, R., F. Lopez-de-Silanes, A. Shleifer, and R. Vishny. 1998. Law and finance. Journal of Political Economy, 106: 1133-55.

[20] Manove, M., O. Padilla and M. Pagano, 2001. Collateral vs. project screening: A model of lazy banks. RAND Journal of Economics, 32/4.

[21] Pagano, M., 1993. Financial markets and growth: An overview. European Economic Review, 37, 613-622.

[22] Saint Paul, G., 1992. Technological choice, financial markets, and economic development. European Economic Review, 36, 763-781.

[23] Tadesse, S., 2002. Financial architecture and economic performance: International evidence. Journal of Financial Intermediation, (4), 429-454. 


\section{Appendix}

\section{Proof of lemma 1}

In equilibrium, financial exchange can take any of the following forms: $i$. bank-finance only; ii. bank and market finance; iii. market-finance only. Given equations (6) and (7), in case $i, r_{l} \geq \gamma$ must hold. Similarly, in case $i i, r_{l}, r_{e} \geq \gamma$ must hold, while in case iii $r_{e} \geq \gamma$. Hence, as one should expected, in any equilibrium with financial exchange, $r_{\text {wacc }} \geq \gamma$ must hold. Therefore, our assumption that $\gamma / g>r-B / \Delta$ is a sufficient condition for entrepreneurs to have a strong incentive to choose type $B$ projects in any equilibrium with financial exchange.

\section{Proof of proposition 1}

Consider an equilibrium with financial exchange with no monitoring. Given lemma 1, entrepreneurs must be choosing type $B$ projects. Financial investors anticipate this behavior. Therefore, according to equations (6) and (7), $r_{l} \geq \gamma / b\left(r_{e} \geq \gamma / b\right)$ must hold for the supply of bank-finance (market-finance) to be positive, which implies $r_{\text {wacc }} \geq \gamma / b$. But then, no equilibrium with financial exchange and no monitoring can ever exist since, given $r+B b<\gamma$ (the NPV of type $B$ projects is negative), $\gamma / b$ strictly exceeds the maximum payment, $r+B$, that entrepreneurs choosing projects of type $B$ can promise to pay. Hence, a necessary condition for an equilibrium with financial exchange is that entrepreneurs are monitored. With monitoring, given equations (6) and (7), $r_{l} \geq \gamma / g+c / l^{d} g, r_{e} \geq \gamma / g$, must hold for the supply of bank finance, and possibly of market finance, to be positive (bank and market finance are both positive if $r_{l}-c / l^{d} g=r_{e}$ ). Therefore, the supply of financial resources is positive only if $r_{\text {wacc }} \geq(c+\gamma) / g$ and is zero otherwise. On the other hand, given equation (8), when entrepreneurs are choosing type $G$ projects, the demand for funds is positive if and only if $r \leq r_{\text {wacc }}$. It then follows that a necessary condition for an equilibrium with financial exchange is $r \geq(c+\gamma) / g$. Moreover, if $r>(c+\gamma) / g$ the only equilibrium amount of financial exchange is uniquely determined and equals $S$. For instance, consider a situation in which $r_{l}$ and $r_{e}$ are such that $r_{w a c c}<(\gamma+c) / g$ so that supply of financial resources is zero. At such values of $r_{\text {wacc }}$, given $r>(c+\gamma) / g$, $r>r_{\text {wacc }}$ holds so that the aggregate demand would be strictly positive: there is an excess of demand of financial resources, so the situation described cannot be an equilibrium. More generally, given $N>S$, the market is characterized by an excess of demand for any $r_{l}$ and $r_{e}$ such that $r_{w a c c}<r$, so that $r_{\text {wacc }}<r$ cannot be an equilibrium. Consider now the situation in which $r_{\text {wacc }}=r$. At this value of $r_{\text {wacc }}$, given $r>(c+\gamma) / g$ the supply of financial resources is strictly positive and equal $S$ As entrepreneurs are indifferent between investing or not, the market clears with a mass of financed entrepreneurs $S$. Therefore, the only possible equilibrium outcome is an amount of financial exchange $S$, with $r_{\text {wacc }}=r$. Differently, in the special case in which $r=(c+\gamma) / g$, the equilibrium amount of financial 
exchange is not uniquely determined. At $r_{w a c c}=(c+\gamma) / g$, which is the only equilibrium value of $r_{w a c c}$, both entrepreneurs and financial investors are indifferent between engaging in financial exchange or not. Hence, any amount of financial exchange between zero and $S$ is a possible equilibrium outcome.

Part $i$. Suppose that there is no disclosure law. Assume a situation where both the supply of market-finance and that of bank-finance are positive. Given equations (6) and (7) this requires $r_{l} \geq r_{e}$, and $r_{l}, r_{e} \geq \gamma / g$, so that $r_{w a c c} \geq \gamma / g$. Given $r_{l} \leq r_{e}$, entrepreneurs equilibrium strategy is to avoid monitoring by financing themselves with enough market-finance and to choose type $B$ projects (lemma 1 applies). This directly implies that in the absence of the disclosure law, the equilibrium can never be characterized by positive supply of market-finance, as this would lead to the choice of type $B$ projects, which is incompatible with the equilibrium, as discussed above. Hence, the only possible equilibrium with financial exchange is one in bank-finance is the only source of finance, $r_{\text {wacc }}=r_{l}$. As discussed above, given $r b+B<\gamma$, a necessary condition for such an equilibrium to exist is that bankers monitor entrepreneurs thereby forcing them to choose type $G$ projects. When entrepreneurs choose type $G$ projects, the maximum return they can pay to bankers is $r$. Accordingly, banker' expected return per entrepreneur, net of monitoring cost, would be $g r-c$, so that given that bankers must earn at least $\gamma$ in expected terms the sufficient condition for an equilibrium with financial exchange, $r>(c+\gamma) / g$, is confirmed. As we already know, if such condition holds, $r_{\text {wacc }}=r$ is the unique equilibrium outcome (with an amount of financial exchange equal to $S$ ) so that, given $r_{w a c c}=r_{l}, r_{l}=r$ follows.

Part ii. According to equation (4) bankers have the incentive to monitor if $l^{d} \geq$ $c / \Delta r_{l}$. In the presence of the disclosure law, given equation (6), with $l^{d} \geq c / \Delta r_{l}$, financial investors are indifferent between supplying bank and market-finance if, $\pi_{b}=g r_{e}$. Also, if bankers are incurring monitoring costs, $\pi_{b}=g r_{e}$ implies $r_{l}>r_{e}$. Given these relationships, we show that $l^{d}=1$ can never be an equilibrium and then characterize the equilibrium with $l^{d}<1$.

Suppose $l^{d}=1$. Then, in equilibrium, $r_{l}=r$ holds. It is immediate to verify that as long as the necessary condition for the existence of an equilibrium with financial exchange, $r \geq(\gamma+c / g), c / \Delta r<1$ follows which means that the amount of bank financed demanded by the entrepreneurs, $l^{d}=1$ exceeds the minimum amount required to give bankers incentives to monitor. But then, given $r_{l}>r_{e}, l^{d}=1$ is not an equilibrium. Starting from a situation in which $l^{d}=1$, entrepreneurs would have the incentive to deviate and reduce their $r_{\text {wacc }}$ by reducing the amount of bank-finance up to $c / \Delta r$ and using an amount $1-c / \Delta r$ of market finance. Note that the entrepreneurs do not have the incentive to set $l^{d}$ below $c / \Delta r$ as the resulting cost of market finance would be $r g / b$ which exceeds the cost of bank-finance $r$.

So the equilibrium must be one in which both bank and market are supplied and $l^{d}=c / r_{l} \Delta$. In any equilibrium where both market-finance and bank-finance are supplied 
$g r_{e} l^{d}=g l^{d} r_{l}-c$ and $l^{d}=c / \Delta r_{l}$ must hold. Combining these two equations, and using the expression for $r_{w a c c}$ together with $r_{w a c c}=r$, gives $r_{e}^{*}=r-c / g$ and $r_{l}^{*}=r_{e}^{*} b / g$ and $l^{d *}=c / \Delta r_{l}^{*}$ as the unique solution. By substituting for the equilibrium value of $r_{l}$ one can verify that $l^{d *}<1$ holds so long as, $r \geq(\gamma+c) / g$, is satisfied.

\section{Proof of Lemma 2}

Part $i$. We assume that $\gamma / \bar{g}>r-B / \Delta_{\max }$. This ensures that moral hazard is still pervasive, i.e. the equivalent of lemma 1 holds. Accordingly, the results reported in proposition 1 for the absence of disclosure law, still hold. In any equilibrium with financial exchange entrepreneurs must be subject to monitoring; given the absence of disclosure law bank-finance is the only source of finance, $l^{d *}=1$, and $r_{l}=r_{w a c c}$. Finally, given $N>S$, $r>(c+\gamma) / g$ is still the sufficient condition for the unique equilibrium outcome to be an amount of financial exchange equal to $S$, with $r_{\text {wacc }}=r$ (Proof of proposition 1, applies). This condition is enough to guarantee the existence a pooling equilibrium. Existence of an equilibrium with screening requires a more stringent condition, see below.

Part ii. Suppose we are in a pooling equilibrium. Given with $r_{l}^{*}=r$, bankers' expected profits are $g r-c$. If a banker decides to screen, her profits would be $\bar{g} r-c-\sigma$. Clearly, pooling is not an equilibrium if

$$
\bar{g} r-c-\sigma>g r-c \Rightarrow r>\frac{\sigma}{\Delta_{\min }}
$$

and is an equilibrium otherwise. By applying the same argument, one can show that screening is an equilibrium if and only if the above inequality holds, so that the equilibrium involves separation through screening if $r \geq \sigma / \Delta_{\min }$ and pooling with no screening otherwise. It is then clear that if $r=\sigma / \Delta_{\min }$ the two equilibria coexist.

\section{Proof of lemma 3}

First of all, we note that $l^{d *}=\frac{c b}{\Delta g r_{e}^{*}}<1$ follows from the fact that we focus on $r>(\gamma+c) / g$. Having said that, a pooling equilibrium, when it exists, is equivalent to the equilibrium with disclosure law discussed in proposition 1, part ii. Given $r>(\gamma+c) / g$, the only equilibrium outcome is $r_{\text {wacc }}=r$, with an amount of financial exchange equal to $S$. So these two conditions must be satisfied by a pooling equilibrium. Moreover, since moral hazard is pervasive, in any equilibrium with financial exchange entrepreneurs must be monitored. Accordingly, $r_{l}>r_{e}$ holds when both market finance and bank finance are supplied in positive amounts. Hence, entrepreneurs have incentive to minimize the use of bank-finance. Therefore, the only equilibrium value of bank-finance in the case of a pooling (bankers are not screening) must be $l^{d}=\min \left(c / \Delta r_{l}, 1\right)$. Combining these conditions yields the equilibrium described in proposition 1 , part ii. 


\section{Proof of lemma 4}

Consider the situation corresponding to the pooling equilibrium described in lemma 3 , with an amount of financial exchange $S$ and $r_{\text {wacc }}=r$. Given $r_{\text {wacc }}^{\prime}$, if an entrepreneur deviates and demands enough bank-finance to induce screening, her expected profits are $\bar{g}\left(r-r_{\text {wacc }}^{\prime}\right)$, while her equilibrium profits are equal to zero, since $r_{w a c c}=r$. Therefore, the pooling equilibrium does not exist, as entrepreneurs will always deviate from it, if $r_{\text {wacc }}^{\prime}<r$. Given the expression for $r_{\text {wacc }}^{\prime}$, it follows that

$$
r_{w a c c}^{\prime}<r \Leftrightarrow r>\bar{r}
$$

If the reverse inequality holds, starting from the initial (pooling) situation, the entrepreneurs do not have incentive to change their strategy. Given $r>(c+\gamma) / g$, financial investors do not have incentive to change their strategy either, so the pooling equilibrium associated with the starting situation exists.

\section{Proof of lemma 5}

A necessary condition for a screening equilibrium is $r_{l} l^{d} \geq \sigma / \Delta_{\min }$ (see equation (13)). Moreover, given equations (6) and (7), $\bar{g} l^{d} r_{l}-c-\sigma=l^{d} \bar{g} r_{e}$ (note that in a screening equilibrium bankers operate both monitoring and screening). This, in turns, implies $r_{e}>$ $r_{l}$, which leads entrepreneurs to minimize the use of bank-finance. Hence, in a screening equilibrium, $l^{d}=\min \left(\sigma / \Delta_{\min } r_{l}, 1\right)$. Given that $r_{l}=r$ holds in an screening equilibrium where $l^{d}=1$, for $l^{d}=1$ to be a screening equilibrium $\sigma / \Delta_{\min } r=1$ must hold, which implies $r=\sigma / \Delta_{\min }$. Otherwise, if $r>\sigma / \Delta_{\min }$ the screening equilibrium, is characterized by the unique levels of $l^{d}<1, r_{e}$ and $r_{l}$, which solve the following system of equations

$$
\begin{array}{r}
l^{d}=\frac{\sigma}{\Delta_{\min } r_{l}} \\
\bar{g} r_{l} l^{d}-c-\sigma=\bar{g} r_{e} l^{d} \\
r=r_{l} l+(1-l) r_{e},
\end{array}
$$

which are $l^{d *}=\frac{\sigma\left(g-\theta \Delta_{\min }\right)}{\bar{g} \Delta_{\min } r_{e}^{*}}, r_{e}^{*}=r-\frac{c+\sigma}{\bar{g}}, r_{l}^{*}=\frac{\bar{g} r_{e}^{S}}{g-\Delta_{\min } \theta}$. Note that $l^{d *}<1$ when $r>\sigma / \Delta_{\min }$. Obviously, if $r<\sigma / \Delta \mathrm{min}$, there exist no screening equilibrium as bankers would have no incentives to screen even when they are the only providers of finance, and appropriate all the return.

\section{Proof of lemma 6}

Note that, given $r \geq \sigma / \Delta_{\min }$ and $r>(c+\gamma) / g, r>(\gamma+c+\sigma) / \bar{g}$. So the only equilibrium outcome is an amount of financial exchange $S$, with $r_{\text {wacc }}=r$. Then, consider the situation corresponding to the screening equilibrium described in lemma 5. Given 
$r_{\text {wacc }}^{\prime \prime}$ if an entrepreneur deviates from the screening equilibrium by demanding an amount $l^{\prime \prime}$ of bank-finance so to induce monitoring without screening, her level of expected profits is $g\left(r-r_{l}^{\prime \prime}\right)$. A screening equilibrium does not exist, as entrepreneurs will always deviate from it, if such level of expected profits exceeds the equilibrium level of profits which is equal to zero, given $r_{\text {wacc }}=r$. Therefore, a screening equilibrium does not exist if $r_{\text {wacc }}^{\prime \prime}<r$

$$
r_{w a c c}^{\prime \prime}<r \Leftrightarrow r<\frac{\sigma+c}{\Delta_{\min }}-\frac{c \theta}{\Delta}
$$

where $\Delta_{\max }=\bar{g}-b$. If the reverse inequality holds, starting from the separating equilibrium situation, the entrepreneurs do not have incentive to change their strategy. As for financial investors, given $r>(\gamma+c+\sigma) / \bar{g}$, they do change their strategy either. Hence, the separating equilibrium with started with, exists.

\section{Proof of proposition 2}

First of all we recall once more that, given $r>(\gamma+c) / g$, the amount of financial exchange is uniquely determined and amounts to $S$ and, in any equilibrium, $r_{\text {wacc }}=g$ must also hold. That given, according to lemma (4) the pooling equilibrium exists if and only if $r \leq \bar{r}$, where we recall that $\bar{r}=\frac{\sigma}{\Delta_{\min }} \frac{\Delta_{\max }}{\Delta_{\min }}-\frac{c}{\Delta_{\min }}$. It is immediate to verify that as long as $\sigma>\widehat{\sigma}, \bar{r}>\frac{\sigma}{\Delta}$, which implies that there exist a non empty set of values of $r,\left[\frac{\sigma}{\Delta_{\min }}, \bar{r}\right]$, for which the pooling equilibrium exists even though screening would be efficient. Moreover, according to lemma (6), the screening equilibrium exists if and only if $r \geq \underline{r}$, where we recall that $\underline{r}=\frac{\sigma}{\Delta_{\min }}+\frac{c}{\Delta_{\min }}-\frac{c}{\Delta} \theta$.

Then, the sufficient condition for the results stated in the proposition is that $\bar{r}>\underline{r}$ holds. If that is true, then as shown in figure 1 , given a level of expected screening costs equal to $\sigma_{1}$, efficient pooling prevails below point $A$, inefficient pooling prevails between $A$ and $B$, inefficient pooling and efficient screening coexist between $B$ and $C$, and efficient screening prevails above $C$.

To prove $\bar{r}>\underline{r}$, we note that $\bar{r}=\underline{r}$ and $d \bar{r} / d \sigma=d \underline{r} / d \sigma$ for $\sigma=\widehat{\sigma}$. Then, since $d \underline{r} / d \sigma$ is a decreasing function of $\sigma$, with

$$
\lim _{\sigma \rightarrow \infty} \frac{d \underline{r}}{d \sigma}=\frac{1}{\Delta_{\min }}<\frac{1}{\Delta_{\min }} \frac{\Delta_{\max }}{\Delta_{\min }}
$$

while $d \bar{r} / d \sigma$ is constant with respect to $\sigma$ and equal to the RHS of the above inequality, our result follows. 
Table 1: Effect of bank and stock market development on per capita growth (1980-1995) ${ }^{\mathrm{a}}$

\begin{tabular}{|c|c|c|c|}
\hline $\begin{array}{l}\text { Explanatory } \\
\text { variables }^{\mathrm{b}}\end{array}$ & $\begin{array}{c}1) \\
\text { OLS } \\
(\text { Centred variables })^{\mathrm{c}}\end{array}$ & $\begin{array}{c}(2) \\
\text { OLS } \\
\text { (Non-centred variables) }\end{array}$ & $\begin{array}{c}(3) \\
\text { OLS } \\
\text { (Non-centred variables) }\end{array}$ \\
\hline INPT & $\begin{array}{c}0.769 \\
(0.259)\end{array}$ & $\begin{array}{c}3.136 \\
(0.265)\end{array}$ & $\begin{array}{c}3.030 \\
(1.759\end{array}$ \\
\hline LINITIAL & $\begin{array}{l}-0.523 \\
(0.265)\end{array}$ & $\begin{array}{l}-0.523 \\
(0.265)\end{array}$ & $\begin{array}{l}-0.5207 \\
(0.316)\end{array}$ \\
\hline BANK & $\begin{array}{c}3.151 \\
(1.256)\end{array}$ & $\begin{array}{c}4.494 \\
(1.567)\end{array}$ & $\begin{array}{c}5.332 \\
(3.515)\end{array}$ \\
\hline TOR & $\begin{array}{c}3.598 \\
(1.154)\end{array}$ & $\begin{array}{c}5.117 \\
(1.652)\end{array}$ & $\begin{array}{c}4.519 \\
(2.183)\end{array}$ \\
\hline INTERACT & $\begin{array}{l}-4.575 \\
(1.715)\end{array}$ & $\begin{array}{l}-4.575 \\
(1.715)\end{array}$ & $\begin{array}{l}-4.954 \\
(1.776)\end{array}$ \\
\hline $\mathrm{TOR}^{2}$ & & & $\begin{array}{l}-0.521 \\
(0.961)\end{array}$ \\
\hline $\mathrm{BANK}^{2}$ & & & $\begin{array}{l}-0.515 \\
(2.498)\end{array}$ \\
\hline $\mathrm{R}^{2}$ & 0.259 & 0.259 & 0.263 \\
\hline NOBS & 71 & 71 & 71 \\
\hline
\end{tabular}

Notes:

${ }^{a}$ Heteroskedasticity-consistent standard errors are reported in parentheses. Bold figures indicate significance at $10 \%$ or less. NOBS indicates the number of observations in a sample.

b The dependent variable is the growth rate of real per capital GDP averaged over 1980-1995. INPT is the intercept. LINITIAL is the logarithm of initial income per capita in 1980. BANK is measured by the ratio of claims on the private sector by deposit money banks as share of GDP averaged over 1980-1995. TOR is turnover ratio measured by total value traded to stock market capitalization averaged over 1980-1995. INTERACT is an interaction term between TOR and BANK.

${ }^{c}$ Centering variables involves subtracting from each observation of the sample the mean of that variable. 
Table 2: Effect of bank and stock market development on per capita growth (19801995)- Robustness analysis ${ }^{\mathrm{a}}$

\begin{tabular}{|c|c|c|c|}
\hline $\begin{array}{l}\text { Explanatory } \\
\text { variables }^{\mathrm{b}}\end{array}$ & $\begin{array}{l}(1) \\
\text { OLS }\end{array}$ & $\begin{array}{l}(2)^{c} \\
\text { IV }\end{array}$ & $\begin{array}{l}\text { (3) } \\
\text { IV }\end{array}$ \\
\hline INPT & $\begin{array}{c}4.832 \\
(2.156)\end{array}$ & $\begin{array}{c}2.779 \\
(3.265)\end{array}$ & $\begin{array}{l}5.434 \\
(4.083\end{array}$ \\
\hline LINITIAL & $\begin{array}{l}-0.611 \\
(0.381)\end{array}$ & $\begin{array}{l}-0.761 \\
(0.341)\end{array}$ & $\begin{array}{l}-0.752 \\
(0.555)\end{array}$ \\
\hline BANK & $\begin{array}{c}2.947 \\
(1.723)\end{array}$ & $\begin{array}{c}8.653 \\
(2.264)\end{array}$ & $\begin{array}{c}4.294 \\
(2.519)\end{array}$ \\
\hline TOR & $\begin{array}{c}4.879 \\
(1.911)\end{array}$ & $\begin{array}{l}10.290 \\
(2.264)\end{array}$ & $\begin{array}{c}5.087 \\
(2.606)\end{array}$ \\
\hline INTERACT & $\begin{array}{l}-4.306 \\
(1.585)\end{array}$ & $\begin{array}{c}-11.265 \\
(5.280)\end{array}$ & $\begin{array}{l}-5.051 \\
(2.941)\end{array}$ \\
\hline NOBS & 60 & 39 & 37 \\
\hline$R^{2}$ & 0.32 & 0.32 & 0.56 \\
\hline $\begin{array}{c}\text { Test of } \\
\text { Overidentyfing } \\
\text { Restrictions }^{\mathrm{d}}\end{array}$ & & $\begin{array}{c}\chi^{2}(4)=3.785 \\
\text { P-value }=0.435\end{array}$ & $\begin{array}{c}\chi^{2}(4)=4.553 \\
\text { P-value }=0.338\end{array}$ \\
\hline
\end{tabular}

Notes:

${ }^{a}$ Heteroskedasticity-consistent standard errors are reported in parentheses. Bold Figures indicate significance of $10 \%$ or less. NOBS is the number of observations.

b The dependent variable is the growth rate of real per capita GDP averaged over 1980-1995. INPT is the intercept. LINITIAL is the logarithm of initial income per capita in 1980. BANK is measured by the ratio of claims on the private sector by deposit money banks as share of GDP averaged over 1980-1995. TOR is turnover ratio measured by total value traded to stock market capitalization averaged over 1980-1995. INTERACT is an interaction term between TOR and BANK. The following list of country controls is included: TRADE is an indicator trade openness measured by real export and imports as share of real GDP averaged over 1980-1995; GOV is indicator of government size measured by government expenditure as share of GDP averaged over 1980-1995; INF is the inflation rate calculated as the log difference of GDP deflator averaged over 1980-1995; BMP is black market premium averaged over 1980-1992; Schooling is an indicator of human capital measured by average schooling years over 25 in 1980. The source for all these data is Demirguc-Kunt and Levine (2001).

c The instruments used are the rule of law, shareholder rights, creditor rights, accounting standards measured by an index and the legal origin of country. The test of over-identifying restrictions statistic is used to test the null that the instruments are not correlated with the error term and hence are valid. The statistic is distributed as chi-squared.

d The regression includes the full list of conditioning variables. 
Figure 1: Prevailing Equilibrium

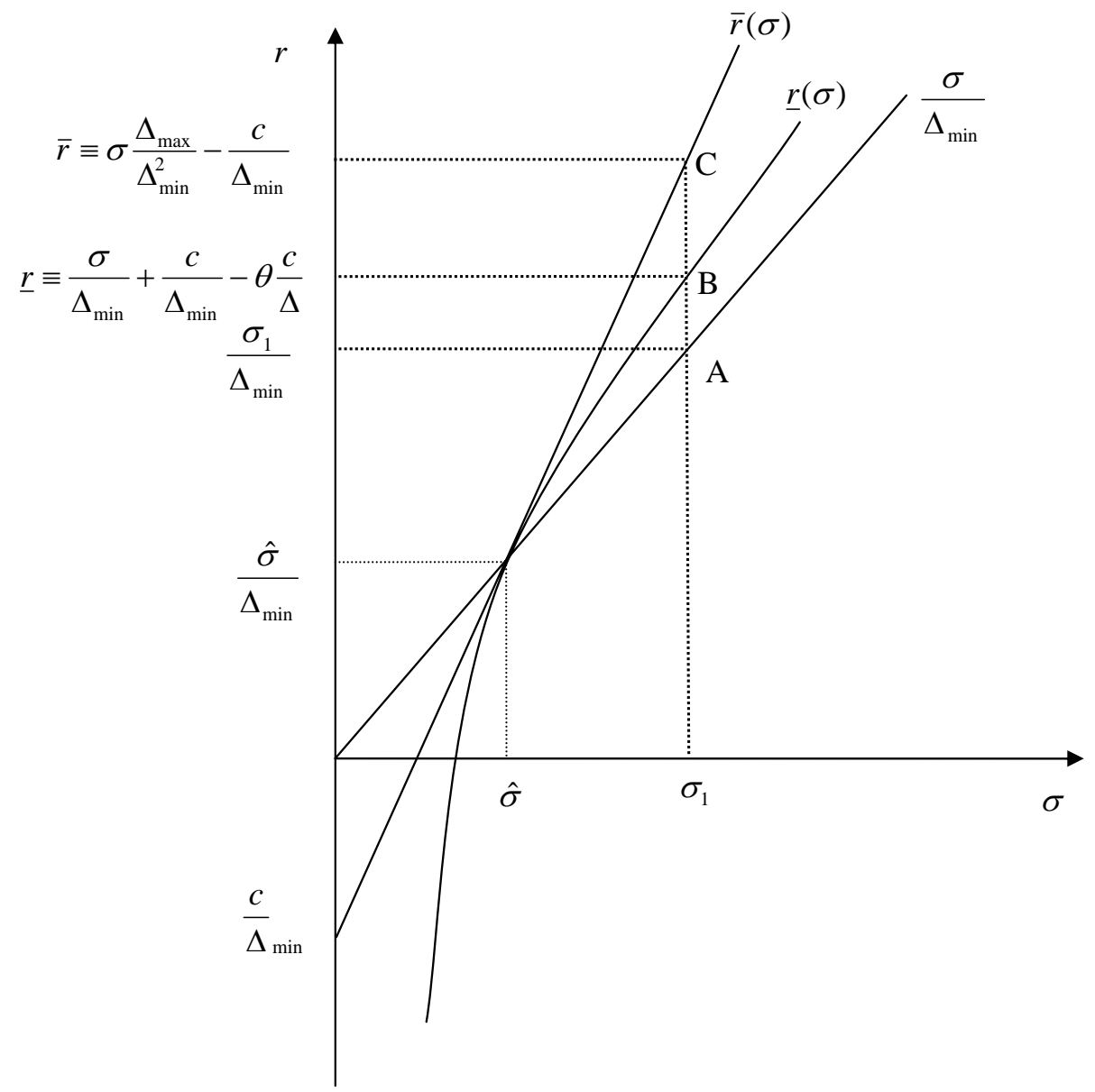


Figure 2: The Growth Impact of Bank at Different Levels of Stock Market Development

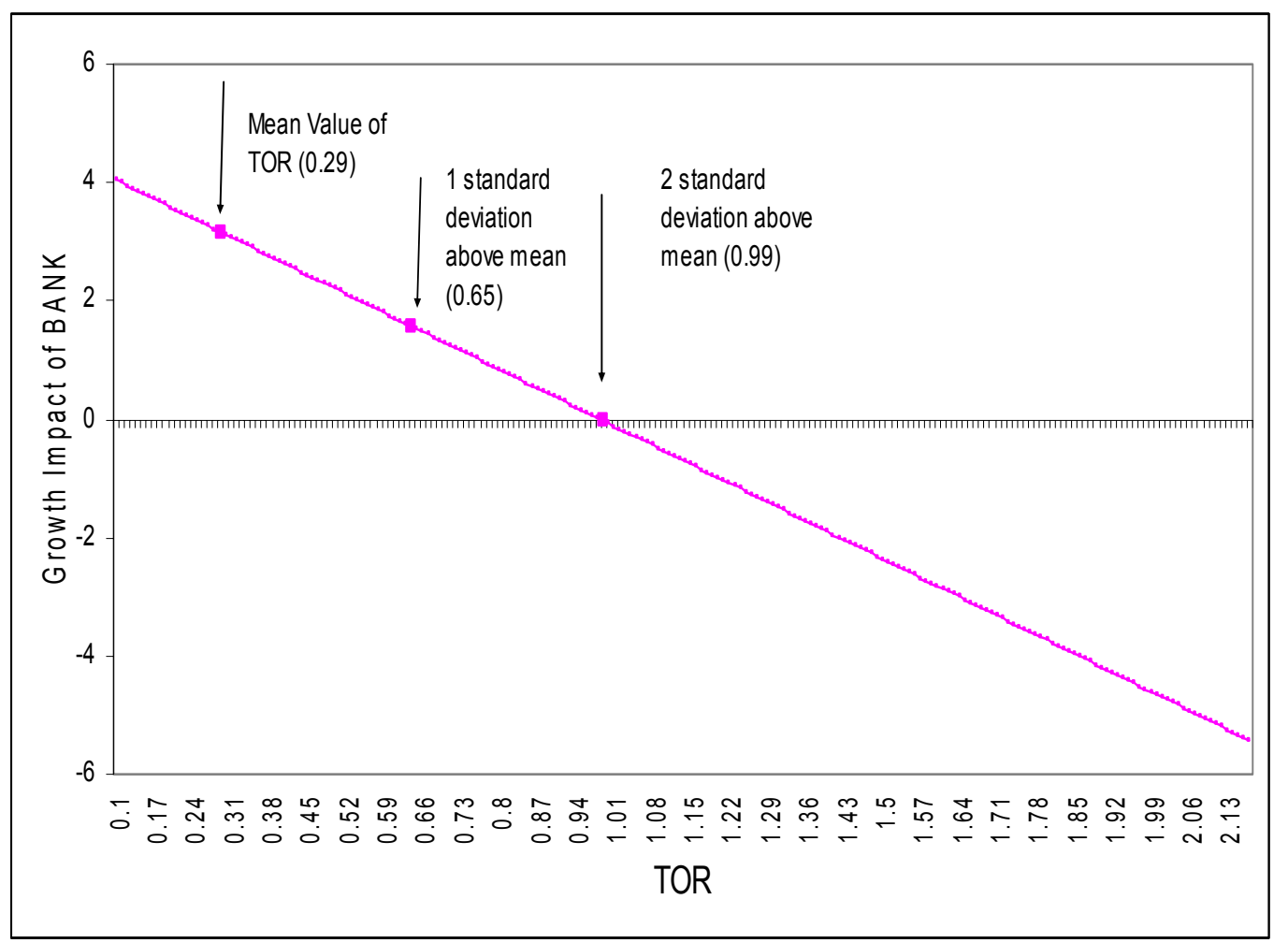

